\title{
Money in Judicial Politics: Individual Contributions and Collective Decisions*
}

\author{
Matias Iaryczower and Matthew Shum ${ }^{\dagger}$
}

January 23, 2012

\begin{abstract}
We study how campaign contributions affect the voting strategies and effectiveness of justices in the Supreme Court of eight US states. A judge's voting strategy leans more heavily towards an interest group the larger are its contributions to the judge, and the smaller are its contributions to other members of the court. This indirect effect is consistent with an equilibrium adjustment to contributions to other members of the court. Observed contributions have a large effect on the behavior of individual judges - affecting both the probability that they vote to overturn a decision of the lower court and the probability that they support an incorrect decision - but they have a small effect on the decisions and effectiveness of the Court.
\end{abstract}

${ }^{*}$ We thank Juliana Bambaci, Claire Lim, Sanford Gordon, and participants at seminars at Yale, and the Political Institutions and Economic Policy, MPSA and AEA conferences, for useful comments. Financial support from NSF Grants SES-1061326 (Iaryczower) and SES-1061266 (Shum) is gratefully acknowledged.

${ }^{\dagger}$ Department of Politics, Princeton University, Princeton NJ 08540, and Division of Humanities and Social Sciences, California Institute of Technology, Pasadena, California 91125, USA, emails: miaryc@princeton.edu,mshum@caltech.edu. 


\section{Introduction}

It is well known that campaign contributions are a key component in the election of politicians. Perhaps less known is that money has also become a central element in the selection and retention of judges in the high courts of the United States. The goal of this paper is to understand how private money affects public decisions in the court.

In contrast with the United States Supreme Court (whose members are appointed by the President with consent of the Senate), more than three quarters of all US states give voters a direct say over the selection and/or retention of judges to their high courts. In twenty two states voters choose members of their Supreme Court in competitive elections, and in another sixteen states voters choose whether to retain incumbents in up-or-down retention elections. And while in the past these judicial elections were low key events, in the last two decades they have become much more similar to their counterparts for legislative and executive seats.

The cases of Pennsylvania and Alabama highlight the extent to which campaign contributions have become central to the election of judges. The average contribution cost per seat in the nine contests for the Pennsylvania Supreme Court between 1993-2009 totaled 3.5M. In Alabama there were twenty seven races for Supreme Court positions between 1994 and 2010, with an average contribution cost per race of 2.25M. The mark was close to or above one million per seat in Ohio (25 races between 1992-2010 at $1.4 \mathrm{M}$ per race), Texas (33 races between 1992-2010 at 1.2M per race), Michigan (21 races between 1990 and 2010 at $1.1 \mathrm{M}$ per race) and Louisiana (17 races between 1992 and 2010 at $0.9 \mathrm{M}$ per race). These numbers are still shy compared to the magnitude of contributions to gubernatorial elections, but they are well above the contributions per seat in most states' assemblies and senates.

The ascent of money in judicial campaigns has become a source of concern for a wide range of interests in society, from media to judges, lawyers, businesses and voters. The generalized perception is that "state courts are drowning in a sea of special-interest campaign money." (New York Times editorial, Sept. 7, 2008). In the words of Justice Sandra Day O'Connor, "judicial elections are becoming political prizefights where partisans and special interests seek to install judges who will answer to them instead of the law and the Constitution." The underlying fear is that money can now influence (either directly, or through the selection of friendly judges) the decisions of many of the high courts in the 
U.S. This fear is shared by voters, business leaders, and the judges themselves. According to a 2001 national poll, $76 \%$ of voters believe campaign contributions affect a judge's courtroom decisions, and more than 35 \% Supreme Court judges say campaign contributions have "some" or "a great deal" of influence on (presumably other) judges' decisions. ${ }^{1}$ A 2007 survey of business by Zogby revealed that $79 \%$ of business leaders believe that campaign contributions made to judges have at least some influence on their decisions in the courtroom.

Clearly, money has become an important factor in judicial politics. But how has money affected judicial outcomes? In this paper, we study how the contributions to a given judge by different interest groups (business, unions, lawyers, and educational organizations) affect the voting behavior of elected judges and the decisions of the court. ${ }^{2}$

Money can affect decision-making strategies in two ways: directly, by changing the bias and competence of the judges sitting in the court, and indirectly, by inducing a strategic response to the strategies of other members of the court. Our first goal is to separate and quantify the direct and indirect channels through which money affects justices' decisions. Do voting strategies change with campaign contributions? Do justices respond strategically to contributions to other members of the court? Our second goal is to evaluate the effect of contributions on the effectiveness of the court. Does money lead to a larger probability of incorrect collective decisions at the court level? To the best of our knowledge, we are the first to quantify the direct and equilibrium impact of contributions on individual decisions and collective outcomes.

To answer these questions, we structurally estimate a model of collective decisionmaking in the court. The structural estimation approach allows us to disentangle the effects of money on justices' inherent preferences and characteristics, and to separate the direct and equilibrium effects of money on their voting strategies. In particular, we recover

\footnotetext{
${ }^{1}$ The Justice at Stake survey polled 188 Supreme Court justices, 527 appellate court judges, and 1713 lower court judges. 35\% of Supreme Court Justices and Appeals courts judges said that campaign contributions have "some" or "a great deal" of influence on (presumably other) judges' decisions. Moreover, only $28 \%$ of Supreme Court justices and $32 \%$ of Appeals courts judges said that campaign contributions have no influence on judges' decisions.

${ }^{2}$ Differently than in other public offices, justices have to justify the reasoning behind their decisions. Because of this, similar legal positions across industries or parties' types will naturally be associated with similar decisions by the same justice. As a result, the aggregate contributions of an interest group - as opposed to the contributions of the particular parties to a given case - can potentially impact the general position taken by a particular justice on a set of legal issues.
} 
justices' types and equilibrium strategies conditional on a large number of observable characteristics of the cases and the justices, including experience variables (prior judicial and political experience, experience in the state supreme court), context variables (measures of the political preferences of voters and politicians at the time of appointment and at the time of decision), and contributions to each judge by interest groups aligned with the sides in each case. ${ }^{3}$

We operationalize the concept of contributions through the money slant of a judge in a given case. We define the money slant as the difference between the proportion of contributions to the judge coming from interest groups favoring overturning and upholding the decision of the lower court.

Our results show that money affects decisions in the court both directly and indirectly. First, we find that a judge's voting strategy leans more heavily towards an interest group the larger are the IG's contributions to the judge. (Moreover, this effect is stronger as the end of term gets closer.) But we also find that a judge's voting strategy leans more heavily towards an interest group the smaller are its contributions to other members of the court. This panel effect of contributions is consistent with an equilibrium adjustment to the response of other members of the court.

To quantify the effect of contributions on collective court decisions, we compute the effect of changing the money slant on the probability that each justice votes to overturn. In particular, we vary the money slant of each justice $i$ from zero to $i$ 's average money slant in cases in which overturning favors lawyers and upholding favors business (we refer to this as the benchmark money slant). Three major conclusions emerge. First, contributions have a large effect on the behavior of individual justices. In Louisiana, for example, three justices are more than $10 \%$ more likely to overturn with the benchmark money slant than in the absence of contributions, while one justice is more than $20 \%$ more likely to uphold

\footnotetext{
${ }^{3}$ The recovered estimates of the effect of money on bias and quality of information reflect the total longrun effect of campaign contributions. This bundles a short-run incentive effect, by which judges sitting in the court adapt their behavior to increase the contributions they expect to receive, and a long-run selection effect operating through replacement (here individual judges do not accommodate their decisions to contributions, but lobbies increase the probability that like-minded candidates win the election by contributing to their campaign). Indeed, our focus on measuring the effects of money on the parameters describing justices' preferences and information differs from that of a number of existing papers, which focus on measuring the causal effects of campaign contributions on the voting behavior of elected officials. The objective here instead is to peer inside the "black box" of the causal effects, in order to uncover how money affects the type and behavior of justices within an equilibrium model of committee voting.
} 
relative to the no-contributions benchmark. Second, the equilibrium effect is generally relevant, and in several courts makes a substantial contribution to the total change in the probability of overturning. Third, we find that while contributions have a relatively large effect on the vote of individual justices, these individual effects typically counteract each other at the court level. Only in two cases we find a non-negligible effect of contributions at the court level. In Louisiana and Texas the court is $2.6 \%$ and $1.6 \%$ more likely to overturn with the benchmark money slant than in the absence of contributions.

Our second goal is to evaluate how money affects the effectiveness of the court. To do this we quantify the effect of contributions on the probability of reaching an incorrect decision. In particular, we compute the effect of changing the money slant (from zero to the benchmark) on the probability of incorrectly overturning and upholding the decision of the lower court. The results highlight the differences between the response of individual justices and that of the court, as a collective body. While in all eight states money significantly changes the probability of mistakes by some members of the court, the influence at the individual level doesn't translate to influence at the level of the court. We find that in all states money increases the probability that the court reaches an incorrect decision, but the effect is generally small in magnitude. ${ }^{4}$ The exceptions are Louisiana (2.6\%) and Texas (1.6\%). That these numbers are almost identical to the effect of the benchmark money slant on the probability of overturning indicates that the larger probability of overturning in the benchmark is almost entirely driven by a larger probability of incorrectly overturning decisions that should be upheld. Thus contributions work, on average, towards promoting mistakes, rather than rectifying mistakes from previous decisions.

The rest of the paper is organized as follows. Section 2 discusses the relation with the literature. Section 3 presents the model of decision-making in the court. Section 4 describes the data and specification of the empirical model. Section 5 presents the main results, and Section 6 concludes. Section 7.3 in the Appendix describes the estimation method employed in this paper.

\footnotetext{
${ }^{4}$ Two mechanisms attenuate the effect on individual errors. First, as we noted before, influence is not uniform. Instead, different justices within the same court are influenced by opposing interests. Second, the court as a collective body is "wiser" than each of its individual components.
} 


\section{$2 \quad$ Related Literature}

The main focus of our paper is on how campaign contributions affect the type and behavior of justices sitting in the court. As such, this paper builds on the literature that studies how elected judges in particular, and elected officials in general, respond to changes in the political environment.

First, a number of recent papers show that elected judges in the U.S. respond to electoral pressures. Brace and Hall (1997) study death penalty decisions in 8 US states. They find that justices in politically liberal states tend to vote more liberally (overturning death sentences) when they are elected in partisan or nonpartisan elections, but not otherwise. Huber and Gordon (2004) analyze trial court sentences of judges in Pennsylvania on aggravated assault, rape and robbery convictions. They argue that because judges discount the future value of retaining office, they become harsher as their terms proceed. They find that sentences for these crimes are significantly longer the closer the sentencing judge is to standing for reelection. Gordon and Huber (2007) analyze data on felony convictions in Kansas, where 14 judicial districts use partisan competitive elections and 17 use retention elections. They find that the sentences of judges in competitive election systems are harsher than those in retention systems. ${ }^{5}$ Lim (2011) uses sentencing data from Kansas to estimate a structural model that fully incorporates career concerns into judges' behavior. ${ }^{6}$ She shows that the sentencing behavior of elected judges is in fact an important determinant of their reelection, and that while the sentencing behavior of appointed judges does not vary much with the political orientation of the district, elected justices tend to be more lenient in liberal leaning districts. ${ }^{7}$ Lim, Snyder, and Strömberg (2010) shows that media coverage of judicial decisions influence the decisions of elected (but not of appointed) judges.

In considering justices' response to electoral pressures, the previous papers focus solely on the influence of voters. The emphasis on voters is natural. It is in fact voters who decide whether to keep an incumbent in office or select an alternative candidate. But a

\footnotetext{
${ }^{5}$ Gordon and Huber (2007) find that the sentences of elected judges become harsher as elections draw closer, but that this is not the case in retention systems. They conclude from this that the incentive effect of the electoral system is more pronounced than its selection effect.

${ }^{6}$ See Diermeier, Keane, and Merlo (2005) for a similar approach in Congress.

${ }^{7}$ More broadly, there is overwhelming evidence showing that judges are sensitive to the political environment. See Hanssen (2000), Besley and Payne (2005) and Canes-Wrone, Clark, and Park (2010) for US states, Gely and Spiller (1990); Spiller and Gely (1992) for the US Supreme Court, Helmke (2002) and Iaryczower, Spiller, and Tommasi $(2002,2006)$ for the Supreme Court in Argentina, among many others.
} 
key component of the fates of candidates running for office in modern day elections is their readiness to reach a large audience effectively. This was long recognized to be the case in races for legislative seats (see for example Jacobson (1978, 1990), Green and Krasno (1988, 1990), Gerber (1998), and Erikson and Palfrey (2000)), and has also become a main ingredient in judicial elections (see Sample, Skaggs, Blitzer, and Casey (2010), Hojnacki and Baum (1992), Champagne (2000, 2004), Iyengar (2001), Bonneau (2005)). ${ }^{8}$ Because of this, campaign contributions have become a central source of influence on candidates running for office.

While it is clear that money affects election results (and thus in our case the characteristics of justices sitting in the court), it is less clear whether money changes the decisions of given elected officials, or, instead, chases like-minded candidates. A small number of papers tackle the difficult problem of trying to establish the direction of causality between money and votes. Bronars and Lott (1997), Stratmann (1991, 2002, 2009), and Kang (2011) study the issue in the US Congress. ${ }^{9}$ De Figueiredo and Edwards (2007) analyze regulatory outcomes in telecommunication. McCall (2003), Cann (2006), and Bonneau and Cann (2010) analyze elected judges. In all, the evidence is non-conclusive, one way or the other.

In this paper we address a different, complementary, question about the relationship between money and decisions in the court. We focus not on trying to disentangle the incentive and selection effects of contributions, but on understanding how money affects (arguably through both mechanisms) the characteristics and voting strategies of the justices ultimately sitting in the court. As far as we are aware, we are the first to quantify the direct and equilibrium impact of contributions on individual decisions and collective outcomes in the court. To do this we follow the approach of Iaryczower and Shum (2011) and Iaryczower, Lewis, and Shum (2011). The idea is to specify a model of decision-making in the court that explicitly allows for both ideology and common values, and estimate the parameters of the model using equilibrium information. Our model of collective decision-making builds on Feddersen and Pesendorfer $(1997,1998)$, and is closest to that of Duggan and Martinelli $(2001) \cdot{ }^{10}$

\footnotetext{
${ }^{8}$ For theoretical contributions studying models of campaign contributions, see Snyder (1990), Snyder (1992), Baron (1994), Grossman and Helpman (1996), Grossman and Helpman (1999), and Prat (2002).

${ }^{9}$ See also Ansolabehere, de Figueiredo, and Snyder Jr. (2003) and the comprehensive review of the literature in this paper.

${ }^{10}$ For structural estimation of ideological models of voting in committees (that do not directly incorporate career concerns) see Poole and Rosenthal (1985, 1991), Heckman and Snyder (1997), Londregan (1999),
} 


\section{A Model of Decision-Making in the Court}

In this section, we describe the model of collective decision-making in the courts. In doing so, we take the parameters of the problem as given, and their dependence on publicly observable characteristics of the choice situation as understood. We make this relation explicit in the estimation (Section 7.3).

The court is composed of $n$ justices, $i=1, \ldots, n$, who consider $T$ independent cases, $t=1, \ldots, T$. In each case $t$, justice $i$ can vote to uphold or overturn the decision of the lower court. We denote this vote by $v_{i}^{t} \in\{0,1\}$, with $v_{i}^{t}=0$ indicating a vote to uphold and $v_{i}^{t}=1$ a vote to overturn the decision of the lower court. The court aggregates the decisions of the individual justices by simple majority rule; i.e. overturns $\left(v_{t}=1\right)$ if $\sum_{i} v_{i}^{t} \geq \frac{n+1}{2}$ and upholds $\left(v_{t}=0\right)$ otherwise.

We consider two related models of individual behavior. In the expressive voting model, we assume that in deciding their vote, justices care only about their individual vote. In the strategic or outcome-oriented voting model, we assume instead that justices care about the decision of the court. We assume that the goal of any justice $i$ in any given case $t$ is that she (in the expressive voting model) or the court (in the strategic voting model) rules according to $i$ 's own best understanding of how the law applies to the particulars of the case. Specifically, before voting in each case $t$, each justice $i$ observes a private signal $s_{i t}=$ $\omega_{t}+\sigma_{i t} \varepsilon_{i t}$, where $\varepsilon_{i t} \sim \mathcal{N}(0,1)$. Here $\omega_{t} \in\{0,1\}$ in an unobservable variable - for both the econometrician and the justices - indicating whether the decision of the lower court should be overturned $\left(\omega_{t}=1\right)$ or upheld $\left(\omega_{t}=0\right)$ according to the law, and $\theta_{i t}=1 / \sigma_{i t}$ is a scale parameter that parametrizes the informativeness of $i$ 's signals. ${ }^{11}$ Justice $i$ has a payoff of $-\pi_{i t} \in(0,1)$ when she/the court incorrectly overturns the lower court $\left(v_{t}=1\right.$ when $\left.\omega_{t}=0\right)$ and of $-\left(1-\pi_{i t}\right)$ when she/the court incorrectly upholds the lower court $\left(v_{t}=0\right.$ when $\left.\omega_{t}=1\right){ }^{12}$ The payoffs of $v_{t}=\omega_{t}=0$ and $v_{t}=\omega_{t}=1$ are normalized to zero. Thus given

Clinton, Jackman, and Rivers (2004) - for the US Congress- and Martin and Quinn (2002, 2007) - for the US Supreme Court. Degan and Merlo (2008) and de Paula and Merlo (2009) consider the nonparametric identification and estimation of the ideological voting model. Coate and Conlin (2004), Coate, Conlin, and Moro (2008), and Kawai and Watanabe (2009) also perform structural estimation of strategic voting (ie. "pivotal voting") models with ideological voters. Iaryczower, Katz, and Saiegh (2009) estimates a model of strategic voting with incomplete information in the US Congress.

${ }^{11}$ We write $\theta_{i t}$ and not simply $\theta_{i}$, invariant in $t$, because in the estimation we will allow the precision of information to depend on characteristics of the case. With identical observable characteristics across cases we would have $\theta_{i t}=\theta_{i}$ for all $t$. The same remark applies to the bias $\pi_{i t}$ below.

${ }^{12}$ Thus, $\pi_{i}<1 / 2$ reflects a bias towards upholding (or towards the Petitioner), while $\pi_{i}>1 / 2$ reflects 
information $\mathcal{I}$, Justice $i$ votes to overturn in case $t$ if and only if $\operatorname{Pr}^{i}\left(\omega_{t}=1 \mid \mathcal{I}\right) \geq \pi_{i t}$, or, equivalently, if and only if $\operatorname{Pr}^{i}\left(\mathcal{I} \mid \omega_{t}=1\right) \mid / \operatorname{Pr}^{i}\left(\mathcal{I} \mid \omega_{t}=0\right) \geq \frac{\pi_{i t}}{1-\pi_{i t}} \frac{1-\rho_{t}}{\rho_{t}}$, where $\rho_{t} \equiv \operatorname{Pr}\left(\omega_{t}=1\right)$ denotes justices' common prior probability that the decision of the lower court should be overturned..$^{13}$

The two alternative models of behavior differ in how much information each justice has in equilibrium. In the expressive voting model, justices care about their own decision, and therefore vote based on their own information $s_{i t}$, i.e., vote to overturn whenever $\operatorname{Pr}^{i}\left(\omega_{t}=1 \mid s_{i t}\right) \geq \pi_{i t}$. Then $\mathcal{I}$ consists only of $s_{i t}$, and $i$ votes to overturn if

$$
\frac{\phi\left(\theta_{i t}\left[s_{i t}-1\right]\right)}{\phi\left(\theta_{i t} s_{i t}\right)} \geq \frac{\pi_{i t}}{1-\pi_{i t}} \frac{1-\rho_{t}}{\rho_{t}}
$$

Let $s_{i t}^{e x p}$ denote the value of $s_{i t}$ that solves (1) with equality. Since $L(s) \equiv \operatorname{Pr}\left(s \mid \omega_{t}=\right.$ $1) / \operatorname{Pr}\left(s \mid \omega_{t}=0\right)$ is increasing in $s, i$ votes to overturn whenever $s_{i t} \geq s_{i t}^{e x p}$, and to uphold. These cutoff points $s_{i t}^{\exp }$ for $i=1, \ldots, n$ completely characterize behavior in the expressive voting case.

In the strategic voting model, justices care about the decision of the court. As a result, any justice $i$ considers the implications of her vote assuming that she is pivotal for the decision. (This supposition is not correct when the justice is not in fact pivotal, but for the same reason these mistakes have no cost for the outcome-oriented justice.) This is relevant because when justices change their vote in response to information, the event that the other justices are evenly split between upholding and overturning is itself a valuable signal for justice $i$.

The informational content of $i$ being pivotal, or decisive, is captured by how likely it is that $i$ is pivotal when the lower court should be overturned, relative to how likely this is when the lower court should be upheld, $L_{\mu}\left(\operatorname{Piv}^{i} ; \theta\right)$. This likelihood ratio depends on the voting strategy profile $\mu$ : if all other justices vote to uphold except when they receive overwhelming evidence that the decision should be overturned, a split court is evidence for

a bias towards overturning (or towards the Respondent). These preconceptions can reflect a variety of factors inducing a non-neutral approach to this case, such as ingrained theoretical arguments about the law, personal experiences, or ideological considerations. They can also capture the effect of money.

${ }^{13}$ Note that since $\omega_{t}$ is assumed to be unobservable, there is always information that would make any two justices disagree about a case. Moreover, if sufficiently biased, two justices can disagree almost always. In particular, with $\pi_{i t} \approx 0$ (or $\pi_{i t} \approx 1$ ), justice $i$ is almost always ideological. On the other hand, when $\pi_{i t}=1 / 2$ for all $i$, the setting boils down to an unbiased, pure common values model. 
overturning, as half of the justices have very strong information towards overturning, while the other half could have only weak evidence towards upholding. $L_{\mu}(\operatorname{Piv} ; \theta)$ also depends on the other justices' quality of information, as not much can be inferred from their votes if their own information is not very precise to begin with.

As in the expressive voting model, the monotone likelihood ratio property of the signals implies that $i$ 's best response to any strategy of the remaining justices is a cutoff strategy, such that $i$ votes to overturn if $s_{i t}$ is above a cutpoint $s_{i t}^{s t}$, and to uphold otherwise. This in turn implies that all responsive equilibria are cutoff equilibria, in which case we can write $L_{\mu}\left(P i v^{i} ; \theta\right)$ simply as a function of the cutpoints, $L\left(P i v^{i} ; \theta, s_{t}^{s t}\right)$. A responsive equilibrium therefore is completely characterized by cutpoints $s_{t}^{s t}=\left(s_{1 t}^{s t}, \ldots, s_{n t}^{s t}\right)$ such that

$$
L\left(\operatorname{Piv}^{i} ; \theta, s_{t}^{s t}\right) \times \frac{\phi\left(\theta_{i t}\left[s_{i t}^{s t}-1\right]\right)}{\phi\left(\theta_{i t} s_{i t}^{s t}\right)}=\frac{\pi_{i t}}{1-\pi_{i t}} \frac{1-\rho_{t}}{\rho_{t}}
$$

(In Appendix 7.2 we derive the more detailed expression for $L\left(P i v^{i} ; \theta, s_{t}^{s t}\right)$ that we use in the estimation.)

Note that when we allow equilibrium strategies to be responsive to external forces such as contributions, the expressive and strategic model imply a markedly different adjustment process. We can think of the total change in strategy $s_{i}^{*}$ as having two parts. A first part (say a direct effect) is a behavioral response to the change in $i$ 's own bias and quality of information. In fact, this is all there is to it in the expressive voting model. But if justices care about the decision of the court, there is also an equilibrium effect, by which changes in the contributions to justice $j$ affect how justice $i \neq j$ votes. Assume for instance that justices' strategies lean towards overturning if contributions for the Petitioner increase, and suppose that this is in fact the case for all judges other than $i$. Then justice $i$ interprets a divided court as more favorable evidence towards upholding. This is because in this case it takes more to convince $(n-1) / 2$ judges to uphold, and less to convince $(n-1) / 2$ judges overturn the decision of the lower court. But this is precisely the situation in which $i$ 's vote changes the decision of the court. As a result, after evaluating the implications of her vote, $i$ becomes more inclined to uphold. This in turn triggers a similar response by other members of the court, etc, until in the new equilibrium no further responses are necessary. We return to this in Section 5.2.

We estimate the model using the two-step approach introduced in Iaryczower and Shum 
(2011). In the first step, we estimate the conditional voting probabilities $\gamma_{i, 0} \equiv \operatorname{Pr}\left(v_{i t}=\right.$ $\left.1 \mid \omega_{t}=0\right)$ and $\gamma_{i, 1} \equiv \operatorname{Pr}\left(v_{i t}=1 \mid \omega_{t}=1\right)$, and the prior $\rho \equiv \operatorname{Pr}\left(\omega_{t}=1\right)$ as a function of characteristics of the justices $Z_{i}$ and the cases $X_{t}$. Using these estimates we recover the equilibrium strategies $s_{i}^{*}=s_{i}^{*}\left(Z_{i}, X_{t}\right)$ and the two structural parameters, $\pi_{i}=\pi_{i}\left(Z_{i}, X_{t}\right)$ and $\theta_{i}=\theta_{i}\left(Z_{i}, X_{t}\right)$, for each justice $i$ using the equilibrium restrictions implied by the model. (We describe our estimation approach in detail in Section 7.3 in the Appendix.)

\section{Money in Judicial Politics: Data and Specification}

The voting data, case-specific information, and most of the non-contribution justice-specific information was available from the State Court Data Project (SCDP) (Brace, Langer, and Hall (2000)), which provides a detailed compilation of data for state Supreme Court criminal and civil cases in all fifty states of the United States during the years 1995 through 1998. Here we consider civil cases related to torts, contracts, and civil government issues. Because of data limitations for contributions records, we focus on only eight states: Alabama, Louisiana, Michigan, Montana, Ohio, Pennsylvania, Texas, and Wisconsin. We also exclude cases in which some justices sitting in the court did not vote. ${ }^{14}$ This results in a sample of 1914 cases across eight states. The SCDP also includes a justice-level dataset, that provides data for each of the 520 justices that served on some court during the period observed. Other sources - the Court Statistics Project at the National Center for State Courts, Marquis' Who's Who, and state Supreme Courts web sites - provided additional biographical information on each of the justices, including background and experience prior to state Supreme Court.

The main variable in the analysis is voting data per se. We classify justices' decisions as either to overturn or uphold the decision of the lower court (in favor of the Petitioner or the Respondent at the Supreme Court level). This coding follows from the fact that appellate courts do not determine liability in civil cases, but instead are responsible for assessing whether or not errors have been committed at trial (Bureau of Justice Statistics).

\footnotetext{
${ }^{14}$ Note that the equilibrium cutpoint of each justice will be different for each different composition of the voting members of the court, implying different conditional probabilities of voting to overturn in each state for each configuration of voting members, even fixing the covariates $X_{t}$. Including only the votes in which all justices vote therefore dramatically reduces the number of parameters to be estimated. This still leaves a significant number of cases in the sample.
} 
Non-monetary Variables. Non-monetary covariates include all case-specific covariates $X_{t}$, and the "non-monetary" justice-specific covariates $Z_{i t}^{N M}$.

Case-specific covariates include the manner in which the State Supreme Court takes jurisdiction (appeal, or others), the type of Petitioner and Respondent (whether business, government - including both local and state governments, or others), the substantive issue under consideration (contracts, torts, or civil government cases), and the legal issue under consideration (evidence, discretion (sentencing and jury instruction), legal standing, and others). Therefore

$X_{t} \delta=$ appeal $_{t} \times \delta_{1}+\left(\begin{array}{c}\text { business }_{t} \times \delta_{2}^{B} \\ + \text { gov }_{t} \times \delta_{2}^{G}\end{array}\right)+\left(\begin{array}{c}\text { contract }_{t} \times \delta_{3}^{C} \\ + \text { tort }_{t} \times \delta_{3}^{T} \\ + \text { civ.gov }_{t} \times \delta_{3}^{C G}\end{array}\right)+\left(\begin{array}{c}\text { evidence }_{t} \times \delta_{4}^{E} \\ + \text { discretion }_{t} \times \delta_{4}^{D} \\ + \text { standing }_{t} \times \delta_{4}^{S}\end{array}\right)$,

and similarly for $X_{t} \eta$. Table 3 in the Appendix summarizes the case-specific data, including the proportion of unanimous and minimal winning votes in each state. ${ }^{15}$

"Non-monetary" justice-specific covariates $Z_{i t}^{N M}$ include (i) "experience" variables, and (ii) "context" variables. The experience variables include (i.a) prior judicial experience (years), (i.b) prior political experience (1/0), and (i.c) experience in the supreme court (years). Context variables include (ii.a) Brace, Langer, and Hall (2000)'s party-adjusted judicial ideology (PAJID) score for each justice at time of appointment, and (ii.b) the (updated version of) Berry et al's citizen (CIT) ideology (Berry, Ringquist, Fording, and Hanson (1998)) for the relevant state in the year in which the decision was made. For both PAJID and CIT, larger values denote a more liberal stance. ${ }^{16}$ To allow the coefficient of CIT to change with the number of years remaining in the term we also include (ii.c) the interaction of CIT with the number of years to end of term (Termremain). Therefore

$$
Z_{i t}^{N M} \alpha^{N M}=\left(\begin{array}{c}
\text { jud.experience } \\
\text { i } \times \alpha_{1}^{J} \\
\text { +pol.experience } \\
\text { pourt.experience } \\
\text { + } \alpha_{1}^{P} \times \alpha_{1}^{C}
\end{array}\right)+\left(\begin{array}{c}
P A J I D_{i} \times \alpha_{2}^{P} \\
+C I T_{i t} \times \alpha_{2}^{C} \\
+\left(C I T_{i t} \times T_{i t}\right) \times \alpha_{2}^{I}
\end{array}\right),
$$

\footnotetext{
${ }^{15}$ While a majority of cases are decided by unanimous decisions, there is also a sizable fraction of nonunanimous decisions.

${ }^{16} \mathrm{CIT}$ is the measure of citizen ideology proposed by Berry et al. The measure infers the ideological position of the electorate from the ideological orientations of members of Congress, as operationalized by interest-group ratings. In particular, Berry et al first estimate CIT in each district of a state by weighting the ideology score for the district's incumbent and challenger with the proportion of votes each received in the election, and then aggregate at the state level. Berry et al also propose a measure of state elite's ideology with a similar procedure, using the ideology of members of congress to estimate the ideological positions of state legislators and the Governor. Brace et al's PAJID variable builds on Berry et al's measures of citizen and elite ideology, but also incorporates information about the political party of each judge.
} 
and similarly for $Z_{i t}^{N M} \zeta^{N M}$. Table 4 in Appendix 7.1 summarizes the non-contributions justice-specific data.

Contributions and the Money Slant. Differently than in other public offices, justices have to justify the reasoning behind their decisions. Because of this, similar legal positions across industries or parties' types will naturally be associated with similar decisions by the same justice. As a result, the aggregate contributions of the group of individuals and organizations sharing a preferred legal position of the court on a given issue can potentially have an impact on the general position taken by a justice on a number of particular cases in which these issues are central. This is the effect of contributions we focus on in this paper. $^{17}$

The interest group itself can be defined in a more broad or narrow way. In our benchmark exercise we will follow a broad view, that corresponds with the accounts of observers in the field, that "Judicial elections have become a multi-million-dollar duel, pitting business and conservative groups against plaintiffs lawyers and unions." (Brennan Center). Because of this, in our benchmark specification we aggregate contributions in four interest groups: business, unions, (non-corporate) lawyers, and education organizations. ${ }^{18,}{ }^{19}$ With the interest groups given, we write $p_{t}=j$ if overturning in case $t$ favors interest group $j$ (if the Petitioner in case $t$ belongs to interest group $j$ ), and similarly $r_{t}=k$ if upholding favors interest group $k$ (if the Respondent in case $t$ belongs to interest group $k$ ). The coding of business, unions and education is straightforward. We code the Petitioner (Respondent) in case $t$ in the lawyers' interest group if (and only if) the issue in the case is tort or civil government and the Petitioner (Respondent) is an individual facing a business or government organization.

We then define the money slant of justice $i$ in case $t$ as the difference between the proportion of contributions to justice $i$ coming from the interest group favoring overturning and the interest group favoring upholding the decision of the lower court. Specifically,

\footnotetext{
${ }^{17} \mathrm{~A}$ second effect is the possible effect of the individual contributions of the parties to a given case. If present, this individual effect would act on top of the interest group effect, inducing a preference for a given party in a given case above what is the standard behavior of the judge on similar issues. We leave tackling this more nuanced individual effect for future research.

${ }^{18}$ In Appendix 7.5 we present results for an alternative classification that distinguishes between different economic interests within Business. The basic gist of the results is qualitatively unchanged.

${ }^{19}$ Because of its limited impact in our sample, removing educational organizations from our interest group definition would leave the results practically unchanged.
} 
letting $c_{i t}(j)$ denote the contributions to judge $i$ by interest group $j$ in $i$ 's most recent election cycle before $t$, the money slant of justice $i$ in case $t$ is

$$
m_{i t}=\frac{c_{i t}\left(p_{t}\right)}{\sum_{j} c_{i t}(j)}-\frac{c_{i t}\left(r_{t}\right)}{\sum_{j} c_{i t}(j)}
$$

We compute the money slant using item level data on contributions made available by the National Institute on Money in State Politics. Implicit in the definition of the money slant is a temporal limit on the set of contributions to be included. The relevant total is the total of contributions to justice $i$ on the most recent election cycle before the year of the decision $t$. Thus, for example, if a justice is elected in 1992 and 1998, and receives contributions in the electoral cycle 1991/92, and in the electoral cycle 1997/98, the relevant contributions for decisions in 1995 and 1996 are those of 1991-92, the relevant contributions for decisions in 1997 are those of 1997, and the relevant contributions for decisions in 1998 are those of 1997-98. If an incumbent justice did not run for election and therefore had no contributions prior to $t$, we take this as zero. However when we do not have contributions data for the previous election of an incumbent (say if the incumbent was elected in 1988), but we know that the incumbent was indeed elected, we take this as missing data.

In the econometric specification, we allow for the possibility that a money slant favoring overturning may have a systematically different effect than a money slant which favors upholding the decision of the lower court. To that end, we include an interaction term of the money slant with an indicator for whether the money slant favors upholding (i.e., $\left.\left\{m_{i t}<0\right\}\right)$. Moreover, to allow the money slant to vary with years to end of term, we also include an interaction of money slant with the variable termremain.

The previous variables capture the effect of $i$ 's money slant on $i$ 's own behavior. And in the expressive voting model, no more is needed, as $i$ 's money slant does not affect $j$ 's behavior. However, in the equilibrium of the strategic voting model, $i$ 's money slant will also change $j$ 's behavior. In a nutshell, if $i$ 's money slant $m_{i}^{\prime}$ in case $t$ induces her to overturn more often than money slant $m_{i}, i$ will demand more information in favor of the Respondent in order to uphold. But then all else equal, the event that $j \neq i$ can change the decision of the court is more likely to arise when there is more information supporting upholding. Because $j$ only cares about the direction of her vote when it has an effect on outcomes, she will update her consideration of the case accordingly (we elaborate on this in Section 5.2). For this reason, we include the variable $m_{-i, t}$, which we define as the average 
money slant of members of the court other than $i$. Thus $Z^{M} \alpha^{M}$ is

$$
Z_{i t}^{M} \alpha^{M}=m_{i t} \times \alpha_{3}+\left(m_{i t} \times I_{\left\{m_{i t}<0\right\}}\right) \times \alpha_{4}+\left(m_{i t} \times T_{i t}\right) \times \alpha_{5}+m_{-i, t} \times \alpha_{6} .
$$

and similarly for $Z_{i t}^{M} \zeta^{M}$.

\section{Results}

A necessary first step to answer the questions we raised in the introduction is to ascertain the effect of campaign contributions on the fundamentals: (i) justices' prior beliefs $\rho_{t}=$ $\rho\left(X_{t}\right)$, and, for each justice $i$, (ii) her bias $\pi_{i t}=\pi\left(Z_{i}, X_{t}\right)$, (iii) quality of information $\theta_{i t}=\theta\left(Z_{i}, X_{t}\right)$, and (iv) strategy $s_{i t}^{*}=s^{*}\left(Z_{i}, X_{t}\right)$. In order to estimate these quantities of interest, we begin by estimating the coefficients of the conditional voting probability functions $\gamma_{1}\left(X_{t}, Z_{i}\right)$ and $\gamma_{0}\left(X_{t}, Z_{i}\right)$, and the prior $\rho\left(X_{t}\right)$. For any given court composition $C$ and case characteristics $X_{t}$, we then use the predicted values of $\gamma_{i, t, 1}=\gamma_{1}\left(X_{t}, Z_{i t}\right)$ and $\gamma_{i, t, 0}=\gamma_{0}\left(X_{t}, Z_{i t}\right)$ for each justice $i$ of $C$ to recover the values of $s_{i t}^{*}, \theta_{i t}$, and $\pi_{i t}$.

Our results, then, have two parts. The first stage MLE estimates of the coefficients of $\rho\left(X_{t}\right), \gamma_{0}\left(X_{t}, Z_{i t}\right)$ and $\gamma_{1}\left(X_{t}, Z_{i t}\right)$ are presented in Table 1 . These results - which we discuss below - offer the first measure of the impact of case and justice-specific covariates on justices' types and strategies, but are difficult to interpret in terms of the magnitude of the effects on the quantities of interest. To describe our main results we compute estimates of the bias, quality of information, and strategies for each state's supreme court, fixing all case-specific covariates at the state-specific sample means, the non-monetary individualspecific covariates at their values for the justices sitting in the court, and the money slant of each justice at various benchmark levels.

We organize the presentation of results as follows. We begin in Section 5.1 by discussing the complete set of estimates for the Supreme Court of Alabama, as an example, to facilitate the interpretation of the main results. We then present the main results in Section 5.2.

\subsection{An Example: The Supreme Court of Alabama}

To fix ideas, we begin by discussing the full set of estimates in an example. Table 1 presents the estimates of prior, bias, quality of information and strategies of each justice in the Alabama Supreme Court across cases, fixing all case-specific covariates at their statespecific sample means, the non-monetary individual-specific covariates at their values for 
the justices sitting in the court, and the average money slant of each justice $i$ in cases in which overturning favors lawyers and upholding favors business. ${ }^{20}$ (For simplicity of exposition, in Table 1 we present point estimates only. Table 6 in Appendix (Section 7.1) provides standard errors of all "second-stage" estimates presented in Table 1. Table 5 in the Appendix presents the point estimates for all courts in the sample.)

[Table 1 about here]

On the leftmost column, we indicate the estimate of the common prior probability that the lower court should be overturned. The number $\rho=0.68$ indicates that on average (for the mix of cases considered by the Alabama Supreme court), and before observing any additional information about the case, justices assign a probability of about $2 / 3$ that the lower court's decision is incorrect and should be overturned. The first two columns present the MLE estimates of the probability that justice $i$ votes to overturn when the decision of the lower court should be upheld $\left(\gamma_{i t 0}\right)$ and the probability that justice $i$ votes to overturn when the decision of the lower court should be overturned $\left(\gamma_{i t 1}\right)$. Thus, for example, justice Alva Maddox had a probability of $\gamma_{i t 1}=0.90$ of (correctly) voting to overturn when the Petitioner should win, and a probability of $1-\gamma_{i t 0}=1-0.02=0.98$ of (correctly) voting to uphold when the Respondent should win.

Column 3 presents the estimate of the quality of the information of each justice. As we pointed out earlier, this estimate is an increasing function of the difference between $\gamma_{i, 1}$ and $\gamma_{i, 0}$. The higher quality-of-information estimate for justice Maddox (3.28) vis a vis that of justice Perry Hooper Sr. (2.89), for example, reflects both a larger probability of correctly voting to overturn (0.90 vs 0.82 ), and a lower probability of incorrectly voting to overturn (0.022 vs 0.024). Column 4 presents the equilibrium cutpoint. This is the signal threshold $s_{i}^{*}$ such that justice $i$ votes to uphold whenever she observes a signal below $s_{i}^{*}$ and to overturn otherwise. Thus for example while justice Maddox would vote to uphold after observing a signal below $s_{M A D}^{*}=0.61$, it would take a signal below $s_{H O U}^{*}=0.52$ for justice Gorman Houston to vote in the same way.

Equilibrium strategies respond to both quality of information and bias. The justices' bias are shown in columns 5 and 6 in the table. Note that in both the strategic and the

\footnotetext{
${ }^{20}$ Because interest groups contributing to justice $i$ enter in different cases as Petitioners and Respondents, averaging over all cases would not be adequate.
} 
expressive voting models, justice Cook is more inclined to overturn than justice Houston, and him in turn more than justice Maddox. In the expressive voting model, for example, for the average case mix, justice Cook requires less evidence (a belief of at least $\pi_{C O O}^{e x p}=0.26$ that the case should be overturned $)$ than justice Houston $\left(\pi_{H O U}^{e x p}=0.73\right)$ and justice Maddox $\left(\pi_{M A D}^{e x p}=0.88\right)$ to vote to overturn. The difference between columns 5 and 6 is due to equilibrium information in the strategic voting model, as captured by the likelihood ratio of the event of being pivotal to the court's decision conditioning on whether the law and the facts of the case favor overturning or upholding (column 7). Given the equilibrium strategies, for seven of the nine justices being pivotal carries information towards upholding. In order to rationalize the same voting behavior, the bias in the strategic voting model for these justices has to be more favorable to overturning than in the expressive voting model. On the other hand, for justices Cook and Kennedy, being pivotal carries information towards overturning. Therefore to rationalize the same voting behavior, the bias in the strategic voting model for these justices has to be more favorable to upholding than in the expressive voting model.

\subsection{The Effect of Contributions on Judicial Decisions}

We can now address our two main questions:

1. What is the effect of campaign contributions on justices' decisions? In particular, how does money change the voting strategies of the justices ultimately sitting on the court? Do justices respond strategically to contributions to other members?

2. What is the effect of campaign contributions on the effectiveness of the court? In particular, does money lead to a larger probability of incorrect decisions?

First Stage Estimates. Our first step is to consider the first-stage coefficient estimates in Table 2. Because changes in justices' bias, expertise and voting strategies will ultimately affect outcomes through the conditional voting probabilities, if $\gamma_{0}$ and $\gamma_{1}$ were to be unresponsive to contributions we would conclude that money has no effect on types and strategies. Instead, the results show that the money slant has a statistically and substantively significant effect on both conditional voting probabilities. 
[Table 2 about here]

The coefficients $\zeta_{3}$ and $\alpha_{3}$ capture the effect of the money slant on $\gamma_{0}$ and $\gamma_{1}$ when $m_{i t}>0$ and the justice served the full term in office. The estimates for $\zeta_{3}$ and $\alpha_{3}$ are both positive and statistically significant. Since $\zeta_{3}=4.36(0.45)>\alpha_{3}=1.81(0.28)>0$ (standard errors in parenthesis), a larger money slant is consistent with a lower cutpoint $s^{*}$; i.e., with a voting strategy that leans more heavily towards overturning. This change in behavior is due to both preferences and information: $\zeta_{3}>>\alpha_{3}$ implies that a larger money slant is consistent with a lower quality of information, and the equilibrium condition (8) in the expressive voting model then implies that a larger money slant is also consistent with an increased bias in favor of overturning (a smaller $\left.\pi_{i}\right) \cdot{ }^{21} \zeta_{5}$ and $\alpha_{5}$ capture the change in the coefficients of the money slant with time remaining in office. The estimates $\zeta_{5}=-0.58(0.12)$ and $\alpha_{5}=0.03(0.02)$ suggest that the effect of the money slant on the conditional voting probabilities and deep parameters is stronger as the end of term gets closer.

The previous discussion focuses on the effect of $i$ 's money slant on her own voting behavior. However, in the equilibrium of the strategic voting model, $i$ 's money slant will also change $j$ 's behavior. To allow for this strategic effect, we allow $j$ 's voting behavior to vary with the money slant of other members of the court. In particular, in our specification, the coefficients $\zeta_{6}$ and $\alpha_{6}$ capture the effect of the average money slant of other members of the court on an individual justice's conditional voting probabilities. Note that in order to be consistent with the strategic voting model, $m_{-i, t}$ should have the opposite effect of $m_{i t}$. This is because when $i$ 's contributions induce her to be more prone to overturning, then all else equal the event that $j \neq i$ can change the decision of the court is more likely to arise when there is more information in favor of upholding the decision of the lower court. As a result, $j$ becomes more prone to upholding. Our estimates of $\zeta_{6}=-1.21(0.39)<0$ and $\alpha_{6}=-2.55(0.34)<0$ are consistent with this interpretation. We discuss these results in more depth below.

\footnotetext{
${ }^{21}$ The coefficients $\zeta_{4}$ and $\alpha_{4}$ capture the change in the coefficient of the money slant on $\gamma_{0}$ and $\gamma_{1}$ when $m_{i t}<0$. Including these interaction terms allows substantial flexibility in how the money slant affects the bias $\pi_{i}$ and quality of information $\theta_{i}$, and then ultimately the voting strategies and conditional probabilities of voting to overturn. The results, however, suggest that the effects of money on the conditional voting probabilities are not qualitatively different depending on whether the money slant favors overturning or upholding. In fact, $\zeta_{4}=1.78(1.49)>\alpha_{4}=0.07(0.05) \simeq 0$.
} 
Direct and Equilibrium Effects of Money on Outcomes. To distinguish between the direct and equilibrium effects of money on vote outcomes, we write the change in strategies $s_{1}^{*}-s_{0}^{*}$ due to a change from an initial money slant $m^{0}$ to money slant $m^{1}$ as:

$$
s_{1}^{*}-s_{0}^{*}=\underbrace{\left(s_{1}^{*}-\tilde{s}_{1}\right)}_{\text {equilibrium effect }}+\underbrace{\left(\tilde{s}_{1}-s_{0}^{*}\right)}_{\text {direct effect }} \text {, }
$$

where $\tilde{s}_{1}$ is the strategy profile that corresponds to $m^{1}$ when we shut down the effect of $m_{-i, t}$ on the conditional voting probabilities for the difference $m^{1}-m^{0}$.

Figure 1 shows the results of this decomposition for the no-slant vector $m^{0}=0$ and the average money slant of each justice $i$ in cases in which overturning favors lawyers and upholding favors business, $m^{1}$, which we adopt as a benchmark for comparison. ${ }^{22}$

[Figure 1 about here]

The left panel plots the overall change in the strategy cutpoint. This shows that changes are larger in magnitude in states in which justices' original strategy leans most towards overturning to begin with (Louisiana, Texas, Montana, and Alabama), and relatively moderate in Ohio and Pennsylvania, where the opposite is true. The right panel shows the decomposition of the total change in strategy in a direct effect and an equilibrium effect. Note that because of the different allocation of contributions across members of the different courts, the direction of the effect is court specific. In Montana, and Ohio, for example, the equilibrium effect generally counteracts the direct effect. In Louisiana and Texas the equilibrium effect is uneven across members of the court.

To evaluate the magnitude of the effect of money on behavior, we compute the effect of changing the money slant from zero to the benchmark $m^{1}$ on the probability that each justice (and the Court) votes to overturn. In particular, we decompose the total change in the direct effect and the equilibrium effect. The result (for each court in the sample) is illustrated in Figure 3.

\footnotetext{
${ }^{22}$ Figure 5 in the Appendix (Section 7.1) plots the empirical distribution of money slant at the justice/case level, along with the empirical distribution of the justice-specific average money slant in our benchmark, $m^{1}$. Note that in a large number of cases the parties to the case are not associated with a lobby contributing to members of the court. Thus for the average case, contributions matter little. It is clear as well that very often this is not the case. This is true at the case/justice level, as well as when we consider average money slant per justice at the benchmark $m^{1}$.
} 
[Figure 3 about here]

Three conclusions emerge. First, contributions have a large effect on the behavior of individual justices. In Louisiana, for example, three justices are more than 10\% more likely to overturn with the benchmark money slant than in the absence of contributions, while one justice is more than $20 \%$ more likely to uphold relative to the no-contributions benchmark. Second, the equilibrium effect is generally consequential. While the magnitude of the equilibrium effects vary substantially by court, in several cases the equilibrium effect has a substantial contribution to the total change in the probability of overturning (this is particularly true in the courts of Montana and Ohio). Third, contributions have a relatively small effect on the probability that the Court overturns the decision of the lower court. This is a major takeaway point: while contributions have a relatively large effect on individual justices, the effect of contributions on the votes of individual justices typically counteract each other at the court level. Only in two cases we find a non-negligible effect of contributions at the court level. In Louisiana, the court is $2.6 \%$ more likely to overturn with the benchmark money slant than in the absence of contributions, and in Texas the change is $1.6 \%$. In both cases the equilibrium effect is relatively important and counteracts the larger direct effects, of about $4.3 \%$ and $2.9 \%$ for Louisiana and Texas respectively.

Money and Mistakes in the Court. Our second goal is to evaluate the effect of campaign contributions on the effectiveness of the court. To do this we quantify the effect of contributions on the probability that an incorrect decision is reached. In particular, we compute the effect of changing the money slant from zero to the benchmark money slant $m^{1}$ on the probability of incorrectly overturning and incorrectly upholding the decision of the lower court.

[Figure 3 about here]

The left panel of Figure 3 plots the probability that the court reaches an incorrect decision at the benchmark money slant. The total probability of an incorrect decision is relatively low for all but two states, Texas and Louisiana, where it reaches $2.5 \%$ and $4 \%$ respectively. The figure also shows the probability of incorrect decisions by type of 
mistake. In both Texas and Louisiana the significant type of error is to overturn incorrectly ( $7 \%$ of the time, and $11 \%$ of the time, respectively), while the probability of upholding a decision that should be overturned is marginal. In Wisconsin and Pennsylvania, instead, the prevailing type of error is to uphold a decision that should be overturned $(1.3 \%$ of the time, and $1.7 \%$ of the time, respectively). The right panel of Figure 3 compares the probability of an incorrect decision at the benchmark money slant vis a vis the error rate with no contributions. In all states, money increases the probability that the court reaches an incorrect decision, but the effect is small in magnitude for all states but Texas and Louisiana, where it accounts for $1.6 \%$ and $2.6 \%$, respectively. Thus, on average money has a relatively low impact on the probability that the court reaches an incorrect decision. However, two important qualifications must be emphasized.

First, note that the effect of money on the probability of mistakes at the court level for Louisiana and Texas is almost identical to the effect of money on the probability of overturning the decision of the lower courts. To understand this result, call $\beta_{o}(m)$ the probability of incorrectly overturning, and $\beta_{u}(m)$ the probability of incorrectly upholding the decision of the lower court given money slant $m$. Then the change in the probability of overturning $\Delta_{o}$ when changing the money slant from $m^{0}$ to $m^{1}$ is

$$
\Delta_{o} \equiv \rho\left[\beta_{u}\left(m^{0}\right)-\beta_{u}\left(m^{1}\right)\right]+(1-\rho)\left[\beta_{o}\left(m^{1}\right)-\beta_{o}\left(m^{0}\right)\right]
$$

while the change in the probability of a mistake $\Delta_{m}$ when changing the money slant from $m^{0}$ to $m^{1}$ is

$$
\Delta_{m} \equiv \rho\left[\beta_{u}\left(m^{1}\right)-\beta_{u}\left(m^{0}\right)\right]+(1-\rho)\left[\beta_{o}\left(m^{1}\right)-\beta_{o}\left(m^{0}\right)\right]
$$

Note that the expressions for $\Delta_{o}$ and $\Delta_{m}$ only differ in the first term, which depends on mistakes with different configuration of contributions conditional on the decision of the lower court being correct. But according to our estimates, both with zero contributions and in the benchmark money slant, the courts of Louisiana and Texas almost never uphold a lower court decision that they should overturn. As a result, $\Delta_{o} \approx \Delta_{m}$. This implies, in particular, that our previous results regarding the effect of the benchmark money slant on the probability that the court overturns are almost entirely driven by a larger probability of incorrectly overturning decisions that should be upheld. Thus contributions work, on average, towards promoting mistakes, rather than rectifying mistakes from previous decisions. 
Second, it should also be noted that while the overall effects on the probability of mistakes are relatively small, this is not because of the absence of a corresponding impact at the individual level. In fact, in all eight states money significantly changes the probability of mistakes of some members of the court. This is illustrated in Figure 4 for the different courts in the sample, which plots the counterfactual effect on the probability that each justice (and the Court) incorrectly votes to overturn (blue bars) and uphold (red bars) when the money slant changes from zero to the benchmark, $m^{1}$.

[Figure 4 about here]

The dampened response at the aggregate level is due to two factors. First, the collective body that is the court is "wiser" than each of its individual components. This is, naturally, an old idea dating back to Condorcet. When each member of the court makes a mistake with probability $x$, the Court makes a mistake with probability smaller than $x$. Second, different justices in the same court receive opposite influence. In Pennsylvania, for example, while the probability that justice Saylor incorrectly overturns increases by $8 \%$, the probability that justice Nigro incorrectly overturns decreases by 7\%. Similarly, in Michigan while the probability that justice Brickley incorrectly overturns increases by $11 \%$, the probability that justice Cavanagh incorrectly upholds increases by $16 \%$. As a result, influence at the individual level doesn't translate to influence in the Court's decision.

\section{Conclusion}

The ascent of money in judicial campaigns has become a source of concern for a wide range of interests in society, from media to judges, lawyers, businesses and voters. The concern is that money can now influence (either directly, or through the selection of friendly judges) the decisions of many of the high courts in the U.S.

In this paper, we study how campaign contributions affect the characteristics and voting behavior of elected judges. To do this we use a structural estimation approach, that allows us to disentangle the effects of money on justices' characteristics and voting strategies. We pose two questions. Our first goal is to disentangle the direct and indirect channels through which money affects justices' decisions. Do voting strategies change with campaign 
contributions? Do justices respond strategically to contributions to other members of the court? Our second goal is to evaluate the effect of contributions on the effectiveness of the court. Does money lead to a larger probability of incorrect decisions?

We show that a judge's voting strategy leans more heavily towards an interest group the larger are its contributions to the judge, and the smaller are its contributions to other members of the court. This indirect effect of contributions is consistent with an equilibrium adjustment to contributions to other members of the court when justices vote strategically and care about the decisions of the court. Our estimates indicate that this equilibrium effect is a meaningful source of variation in justices' voting behavior. To quantify the effect of contributions on the decisions of the court we compute the effect of changing the money slant (i) on the probability that each justice votes to overturn and (ii) on the probability that each judge votes incorrectly. We show that in both cases the observed contributions have a large effect on the behavior of individual judges, but only a small effect on the decisions and effectiveness of the Court.

While our analysis was limited to judicial decisions, elected judges are in many ways, similar to politicians. Because of this, we believe that our results bring about broader lessons on the effect of contributions on policy decisions. In particular, our results suggest that more research is needed in the court, as well as in legislatures and other collective bodies, to understand the panel effects shaping committee members' response to contributions.

Understanding more fully the effect of money on public policy is particularly critical in light of the recent decision by the United States Supreme Court (Citizens United v. Federal Election Commission) freeing corporations from restrictions on political spending in elections. Much work remains ahead. First, we aim to bring forward into our analysis the contribution decisions of the interest groups. This will allow us to better understand the motives and strategies of different interest groups, and how they relate to the outcomes we observe in terms of the characteristics and strategies of the justices sitting in the court. Second, we aim to expand the temporal coverage of our analysis. Because of data availability, our analysis was based on cases considered between 1995 and 1998, and therefore on contributions given between 1990 and 1998. But the issues considered here only became more salient since then, with business associations responding to the overwhelming pres- 
ence of lawyers in contributions that were typical of the 90's. This requires a considerable effort in data collection, to extend the coverage of state Supreme Courts decisions (as in the SCDP) to the present. We hope to be able to contribute in this area as well. Finally, we aim to extend our analysis to other political offices, in order to better understand how money shapes public policy across different issue areas and branches of government. 


\section{References}

Ansolabehere, S., J. M. de Figueiredo, And J. M. Snyder JR. (2003): "Why Is There so Little Money in U.S. Politics?," Journal of Economic Perspectives, 17(1), 105-130.

BAron, D. P. (1994): "Electoral Competition with Informed and Uninformed Voters," American Political Science Review, 88, 33-47.

Berry, W., E. Ringquist, R. Fording, and R. Hanson (1998): "Measuring Citizen and Government Ideology in the American States, 1960-93," American Journal of Political Science, $42(1), 327-348$.

Besley, T. J., And A. A. Payne (2005): "Implementation of Anti-Discrimination Policy: Does Judicial Selection Matter?," LSE STICERD Research Paper No. PEPP04.

Bonneau, C. W. (2005): "What Price Justice(s)? Understanding Campaign Spending in State Supreme Court Elections," State Politics 83 Policy Quarterly, 5, 107-124.

Bonneau, C. W., And D. M. Cann (2010): "The Effect of Campaign Contributions on Judicial Decisionmaking," Typeset.

Brace, P., And M. Hall (1997): "The Interplay of Preferences, Case Facts, Context, and Rules in the Politics of Judicial Choice," The Journal of Politics, 59(4), 1206-1231.

Brace, P., L. Langer, and M. Hall (2000): "Measuring the Preferences of State Supreme Court Judges," The Journal of Politics, 66(2), 387-413.

Bronars, S. G., And J. R. LotT (1997): "Do Campaign Donations Alter How a Politician Votes? Or, Do Donors Support Candidates Who Value the Same Things That They Do?," Journal of Law and Economics, 40(2), 317-350.

Canes-Wrone, B., T. S. Clark, And J.-K. Park (2010): "Judicial Independence and Retention Elections," Forthcoming, Journal of Law, Economics and Organization.

Cann, D. M. (2006): "Justice for Sale? Campaign Contributions and Judicial Decision Making," Typeset.

Champagne, A. (2000): "Interest Groups and Judicial Elections," Loyola of Los Angeles Law Review, 34, 1391-1409.

- (2004): "Tort Reform and Judicial Selection," Loyola of Los Angeles Law Review, 38, $1483-1515$.

Clinton, J. D., S. Jackman, and D. Rivers (2004): "The Statistical Analysis of Roll Call Data," American Political Science Review, 55, 355-370.

Coate, S., And M. Conlin (2004): "A Group Rule-Utilitarian Approach to Voter Turnout: Theory and Evidence," American Economic Review, 94, 1476-1504. 
Conte, S., M. Conlin, And A. Moro (2008): "The performance of pivotal-voter models in small-scale elections: Evidence from Texas liquor referenda," Journal of Public Economics, 92, $582-596$.

Degan, A., And A. Merlo (2008): "Do Voters Vote Ideologically?," Working Paper, U. Penn.

De Figueiredo, R. J., And G. Edwards (2007): "Does Private Money Buy Public Policy? Campaign Contributions and Regulatory Outcomes in Telecommunications," Journal of Economics $\&$ Management Strategy, 16, 547-576.

de Paula, A., And A. Merlo (2009): "Identification and Estimation of Preference Distributions when Voters are Ideological," Working Paper, U. Penn.

Diermeier, D., M. Keane, and A. Merlo (2005): "A Political Economy Model of Congressional Careers," American Economic Review, pp. 347-373.

Duggan, J., And C. Martinelli (2001): "A Bayesian Model of Voting in Juries," Games and Economic Behavior, 37, 259-294.

Erikson, R., And T. Palfrey (2000): "Equilibria in Campaign Spending Games: Theory and Data," American Political Science Review, 94, 595-609.

Feddersen, T., And W. Pesendorfer (1997): "Voting Behavior and Information Aggregation in Elections With Private Information," Econometrica, 65, 1029-1058.

(1998): "Convicting the Innocent: The Inferiority of Unanimous Jury Verdicts under Strategic Voting," American Political Science Review, 92, 23-35.

Gely, R., And P. SpIller (1990): "A Rational Choice Theory of Supreme Court Statutory Decisions with Applications to the "State Farm" and "Grove City Cases"," Journal of Law, Economics and Organization, 6(2), 263-300.

Gerber, A. (1998): "Estimating the Effect of Campaign Spending on Senate Election Outcomes Using Instrumental Variables," American Political Science Review, (2), 401-411.

Gordon, S., And G. Huber (2007): "The Effect of Electoral Competitiveness on Incumbent Behavior," Quarterly Journal of Political Science, pp. 107-138.

Green, D. P., And J. S. Krasno (1988): "Salvation for the Spendthrift Incumbent: Reestimating the Effects of Campaign Spending in House Elections," American Journal of Political Science, 32, 884-907.

- (1990): "Rebuttal to Jacobson's "New Evidence for Old Arguments"," American Journal of Political Science, 34, 363-372.

Grossman, G. M., And E. Helpman (1996): "Electoral Competition and Special Interest Politics," The Review of Economic Studies, 63(2), 265-286.

524.

(1999): "Competing for Endorsements," The American Economic Review, 89(3), 501- 
Hanssen, A. (2000): "Independent Courts and Administrative Agencies: an Empirical Analysis of the States," Journal of Law, Economics and Organization, 16(2), 534-571.

Heckman, J., And J. J. Snyder (1997): "Linear Probability Models of the Demand for Attributes with an Empirical Application to Estimating the Preferences of Legislators," The RAND Journal of Economics, 28(0), S142-S189, Special Issue in Honor of Richard E. Quandt.

Helmke, G. (2002): "The Logic of Strategic Defection: Court-Executive Relations in Argentina under Dictatorship and Democracy," American Political Science Review, 96(2), 291-303.

Hojnacki, M., And L. Baum (1992): "Choosing Judicial Candidates: How Voters Explain Their Decisions," Judicature, 75(6), 300-309.

Huber, G. A., And S. C. Gordon (2004): "Accountability and Coercion: Is Justice Blind When It Runs for Office?," American Journal of Political Science, 48, 247-263.

IARyczower, M., G. Katz, And S. SAiegh (2009): "Voting in the Bicameral Congress: Large Majorities as a Signal of Quality.," HSS, California Institute of Technology.

IAryczower, M., G. Lewis, And M. Shum (2011): "To Elect or to Appoint? Bias, Information, and Responsiveness of Bureaucrats and Politicians," HSS Working Paper 1323, California Institute of Technology.

IARyczower, M., And M. Shum (2011): "The Value of Information in the Court. Get it Right, Keep it Tight.," Forthcoming, American Economic Review.

Iaryczower, M., P. Spiller, And M. Tommasi (2002): "Judicial Independence in Unstable Environments, Argentina 1935-1998," American Journal of Political Science, 46(4), 699-716.

Iaryczower, M., P. Spiller, And M. Tommasi (2006): "Judicial Lobbying: The Politics of Labor Law Constitutional Interpretation," American Political Science Review, 100, 85-97.

IYengaR, S. (2001): "Effects of Media-Based Campaigns on Candidate and Voter Behavior: Implications for Judicial Elections," Indiana Law Review, 35, 691-699.

Jacobson, G. C. (1978): "The Effects of Campaign Spending in Congressional Elections," The American Political Science Review, 72(2), 469-491.

(1990): "The Effects of Campaign Spending in House Elections: New Evidence for Old Arguments," American Journal of Political Science, 34(2), 334-362.

KAnG, K. (2011): "Lobbying for Power: a Structural Model of Lobbying in the Energy Sector," working paper, University of Pennsylvania.

Kawai, K., And Y. Watanabe (2009): "Inferring Strategic Voting," Northwestern University, Department of Economics.

Lim, C. (2011): "Turnover and Accountability of Appointed and Elected Judges," Typeset, Stanford University. 
Lim, C., J. M. Snyder, And D. Strömberg (2010): "Measuring Media Influence on U.S. State Courts.," Typeset, Stanford University.

Londregan, J. (1999): "Estimating Legislators' Preferred Points," Political Analysis, 8(1), 3556.

Martin, A., And K. Quinn (2002): "Dynamic ideal point estimation via Markov chain Monte Carlo for the US Supreme Court, 1953-1999," Political Analysis, 10(2), 134-153.

(2007): "Assessing Preference Change on the US Supreme Court," Journal of Law, Economics and Organization, 23(2), 365-385.

McCall, M. (2003): "The Politics of Judicial Elections: The Influence of Campaign Contributions on the Voting Patterns of Texas Supreme Court Justices, 1994-1997," Politics ES Policy, $31,314-343$.

Poole, K., And H. Rosenthal (1985): "A Spatial Model for Legislative Roll Call Analysis," American Journal of Political Science, 29, 357-384. $228-278$.

Prat, A. (2002): "Campaign Spending with Office-Seeking Politicians, Rational Voters, and Multiple Lobbies," Journal of Economic Theory, 103, 162-189.

Sample, J., A. Skaggs, J. Blitzer, and L. Casey (2010): "The New Politics of Judicial Elections 2000-2009," Discussion paper, Brennan Center for Justice.

SNyder, J. (1990): "Campaign Contributions as Investments: The U.S. House of Representatives, 1980-1986," The Journal of Political Economy, 98(6), 1195-1227.

Snyder, J. M. (1992): "Long-Term Investing in Politicians: Or, Give Early, Give Often," Journal of Law \& Economics, 35, 15-43.

Spiller, P., And R. Gely (1992): "Congressional Control or Judicial Independence: The Determinants of U.S. Supreme Court Labor-Relations Decisions, 1949-1988," The RAND Journal of Economics, 23(4), 463-492.

Stratmann, T. (1991): "What Do Campaign Contributions Buy? Deciphering Causal Effects of Money and Votes," Southern Economic Journal, 57(3), 606-620.

(2002): "Can Special Interests Buy Congressional Votes? Evidence from Financial Services Legislation," Journal of Law \& Economics, 45(2), 345-374.

(2009): "How Prices Matter in Politics: The Returns to Campaign Advertising," Public Choice. 
Table 1: Example: The Supreme Court of Alabama

\begin{tabular}{|c|c|c|c|c|c|c|c|c|}
\hline & Justice & $\gamma_{i t 0}$ & $\gamma_{i t 1}$ & $\theta$ & $s^{*}$ & $\pi^{\exp }$ & $\pi^{S T}$ & $L($ piv $)$ \\
\hline \multirow{9}{*}{$\begin{array}{c}\text { Alabama } \\
(\rho=0.68)\end{array}$} & Almon, Reneau P & 0.050 & 0.919 & 3.046 & 0.541 & 0.762 & 0.591 & 0.452 \\
\hline & Cook, Ralph D. & 0.282 & 0.977 & 2.575 & 0.224 & 0.259 & 0.421 & 2.078 \\
\hline & Houston, Gorman & 0.056 & 0.926 & 3.038 & 0.524 & 0.731 & 0.574 & 0.495 \\
\hline & Kennedy, Mark & 0.317 & 0.982 & 2.585 & 0.185 & 0.209 & 0.388 & 2.388 \\
\hline & Maddox, Alva Hugh & 0.022 & 0.897 & 3.285 & 0.615 & 0.883 & 0.708 & 0.322 \\
\hline & Shores, Janie L. & 0.047 & 0.923 & 3.099 & 0.540 & 0.761 & 0.593 & 0.458 \\
\hline & Hooper Sr., Perry O. & 0.024 & 0.817 & 2.890 & 0.687 & 0.912 & 0.695 & 0.220 \\
\hline & Lyons, Champ Jr. & 0.072 & 0.925 & 2.898 & 0.504 & 0.692 & 0.554 & 0.552 \\
\hline & See, Harold F. & 0.076 & 0.917 & 2.814 & 0.509 & 0.700 & 0.556 & 0.538 \\
\hline
\end{tabular}


Table 2: Coefficients of the common prior function $\rho\left(X_{t}\right)$, and the individual statecontingent probabilities of voting to overturn the decision of the lower court, $\gamma_{0}\left(X_{t}, Z_{i t}\right)$ and $\gamma_{1}\left(X_{t}, Z_{i t}\right)$.

\begin{tabular}{|c|c|c|c|c|}
\hline & & $\rho$ & $\gamma_{i t 0}$ & $\gamma_{i t 1}$ \\
\hline \multirow{22}{*}{$\begin{array}{c}\text { Case } \\
\text { Specific }\end{array}$} & \multirow{2}{*}{ Constant } & 1.835 & 0.941 & 4.973 \\
\hline & & (18.954) & (9.702) & (42.177) \\
\hline & \multirow[b]{2}{*}{ Appeal } & -0.704 & -0.099 & -0.473 \\
\hline & & $-(6.185)$ & $-(3.290)$ & $-(12.344)$ \\
\hline & \multirow{2}{*}{ Petitioner:Business } & -0.197 & 1.420 & 1.583 \\
\hline & & $-(2.500)$ & (11.023) & (9.642) \\
\hline & \multirow{2}{*}{ Petitioner:Govt } & -0.248 & 0.449 & 0.192 \\
\hline & & $-(2.746)$ & $(5.256)$ & $(4.257)$ \\
\hline & \multirow{2}{*}{ Respondent:Business } & -0.832 & 0.137 & 0.342 \\
\hline & & $-(3.892)$ & $(2.660)$ & (4.676) \\
\hline & \multirow{2}{*}{ Respondent:Govt } & -0.911 & -0.248 & 0.569 \\
\hline & & $-(7.522)$ & $-(4.093)$ & (9.554) \\
\hline & \multirow{2}{*}{ Issue:Contracts } & 0.491 & -0.774 & -0.117 \\
\hline & & (3.340) & $-(4.584)$ & $-(4.045)$ \\
\hline & \multirow{2}{*}{ Issue:Torts } & -0.102 & -0.434 & 0.258 \\
\hline & & $-(2.261)$ & $-(4.653)$ & (7.314) \\
\hline & \multirow{2}{*}{ Legal:Discretion } & -0.340 & -0.960 & -0.344 \\
\hline & & $-(4.655)$ & $-(8.660)$ & $-(8.456)$ \\
\hline & \multirow{2}{*}{ Legal:Evidence } & -0.124 & -0.842 & -0.559 \\
\hline & & $-(2.292)$ & $-(5.650)$ & $-(6.757)$ \\
\hline & \multirow{2}{*}{ Legal:Standing } & -0.530 & 0.273 & -0.432 \\
\hline & & $-(3.647)$ & (4.339) & $-(5.980)$ \\
\hline \multirow{6}{*}{$\begin{array}{l}\text { Justice } \\
\text { Specific }\end{array}$} & \multirow{4}{*}{ Judicial E } & & -0.005 & 0.005 \\
\hline & & & $-(4.469)$ & (9.000) \\
\hline & & & 0.009 & -0.008 \\
\hline & & & (4.057) & $-(4.017)$ \\
\hline & \multirow{2}{*}{ Political Experience } & & 0.298 & 0.679 \\
\hline & & & (3.159) & (6.636) \\
\hline \multirow{11}{*}{$\begin{array}{c}\text { Justice/Case } \\
\text { Specific }\end{array}$} & $\begin{array}{l}\text { Years of Experience } \\
\text { in the Court }\end{array}$ & & $\begin{array}{r}-0.024 \\
-(4.906)\end{array}$ & $\begin{array}{r}0.004 \\
(5.339)\end{array}$ \\
\hline & \multirow{2}{*}{ CIT } & & -0.063 & -0.066 \\
\hline & & & $-(27.298)$ & $-(24.465)$ \\
\hline & \multirow{2}{*}{ CIT * Termremain } & & 0.000 & 0.000 \\
\hline & & & $-(1.921)$ & (1.257) \\
\hline & Money Slant & & 4.358 & 1.811 \\
\hline & Money Slant * & & $\begin{array}{r}1783 \\
17871)\end{array}$ & $\begin{array}{r}(0.508) \\
0.073\end{array}$ \\
\hline & ProRespondent & & $\begin{array}{l}1.100 \\
(1.197)\end{array}$ & (1.534) \\
\hline & Money Slant (-i) & & $\begin{array}{l}-1.209 \\
-(3078)\end{array}$ & -2.550 \\
\hline & Money Slant * & & $\begin{array}{r}-(3.078) \\
-0.579\end{array}$ & $\begin{array}{r}-(7.449) \\
0.033\end{array}$ \\
\hline & Termremain & & $-(4.739)$ & (1.444) \\
\hline
\end{tabular}

Note: t-statistics in parenthesis. 

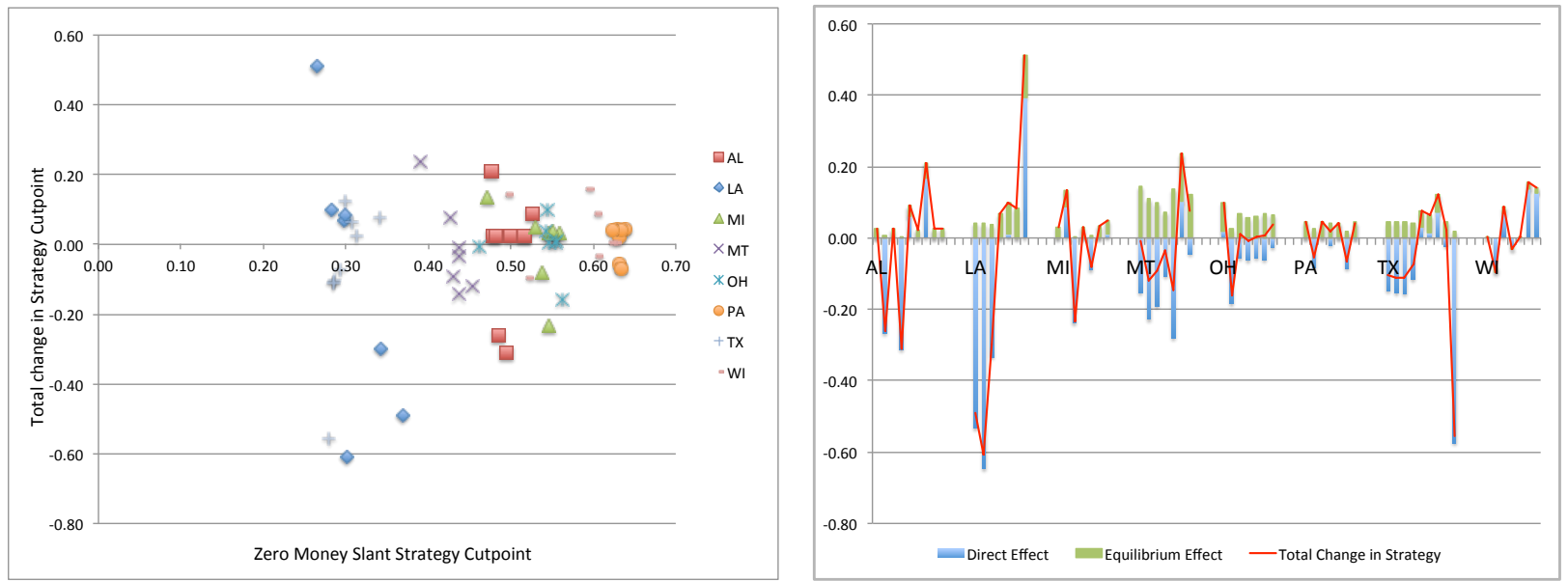

Figure 1: Left panel shows the change in justices' strategies associated with a change in money slant from zero to the benchmark money slant (left panel). Right panel shows the decomposition of this change in a direct effect and an equilibrium effect.
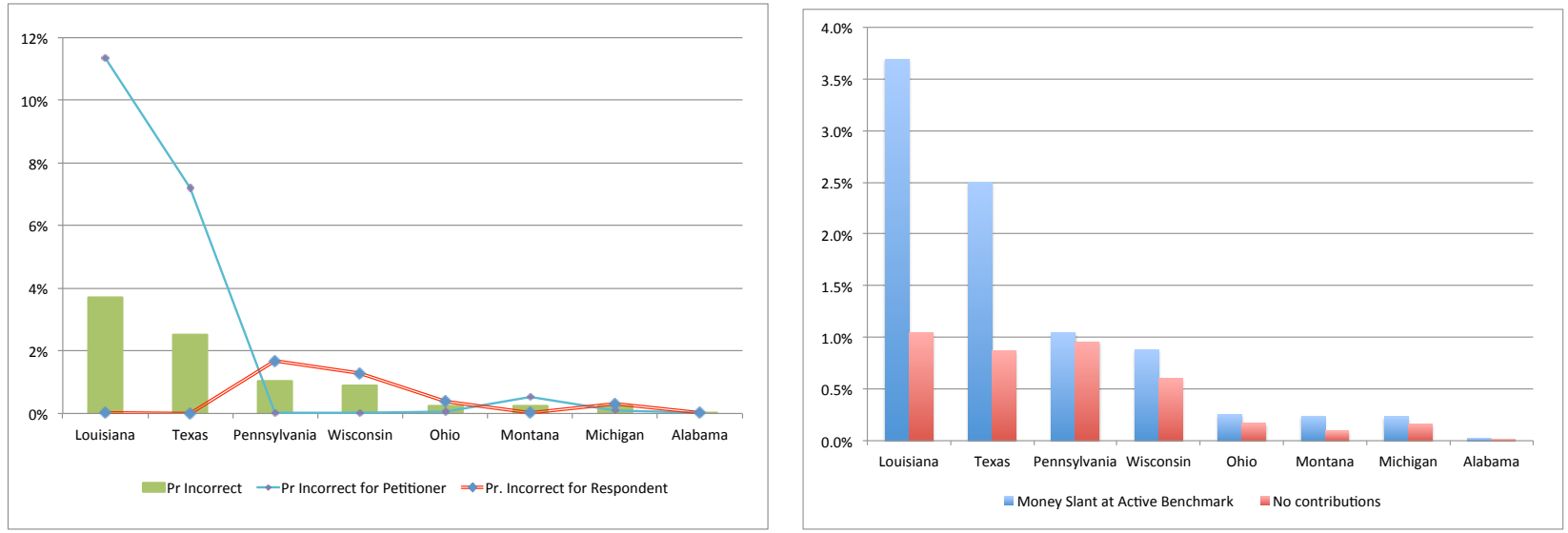

Figure 2: The left panel plots the probability of an incorrect decision at the benchmark money slant. The right panel shows a comparison with the case of zero contributions. 

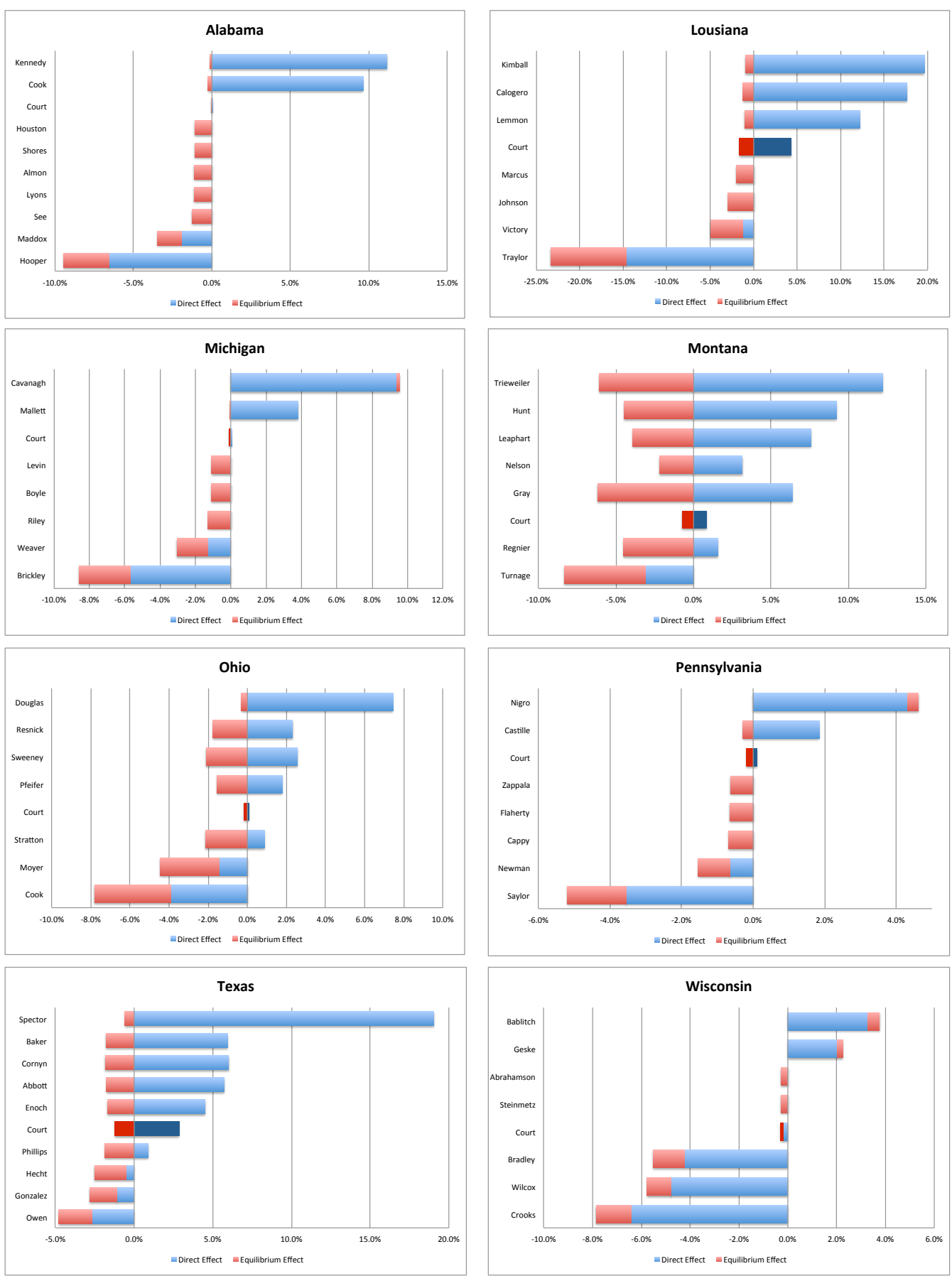

Figure 3: Counterfactual effect on the probability that each justice (and the Court) votes to overturn when the money slant changes from zero to the benchmark, $m^{1}$. The total change is decomposed in a direct effect (blue bars) and an equilibrium effect (red bars). 

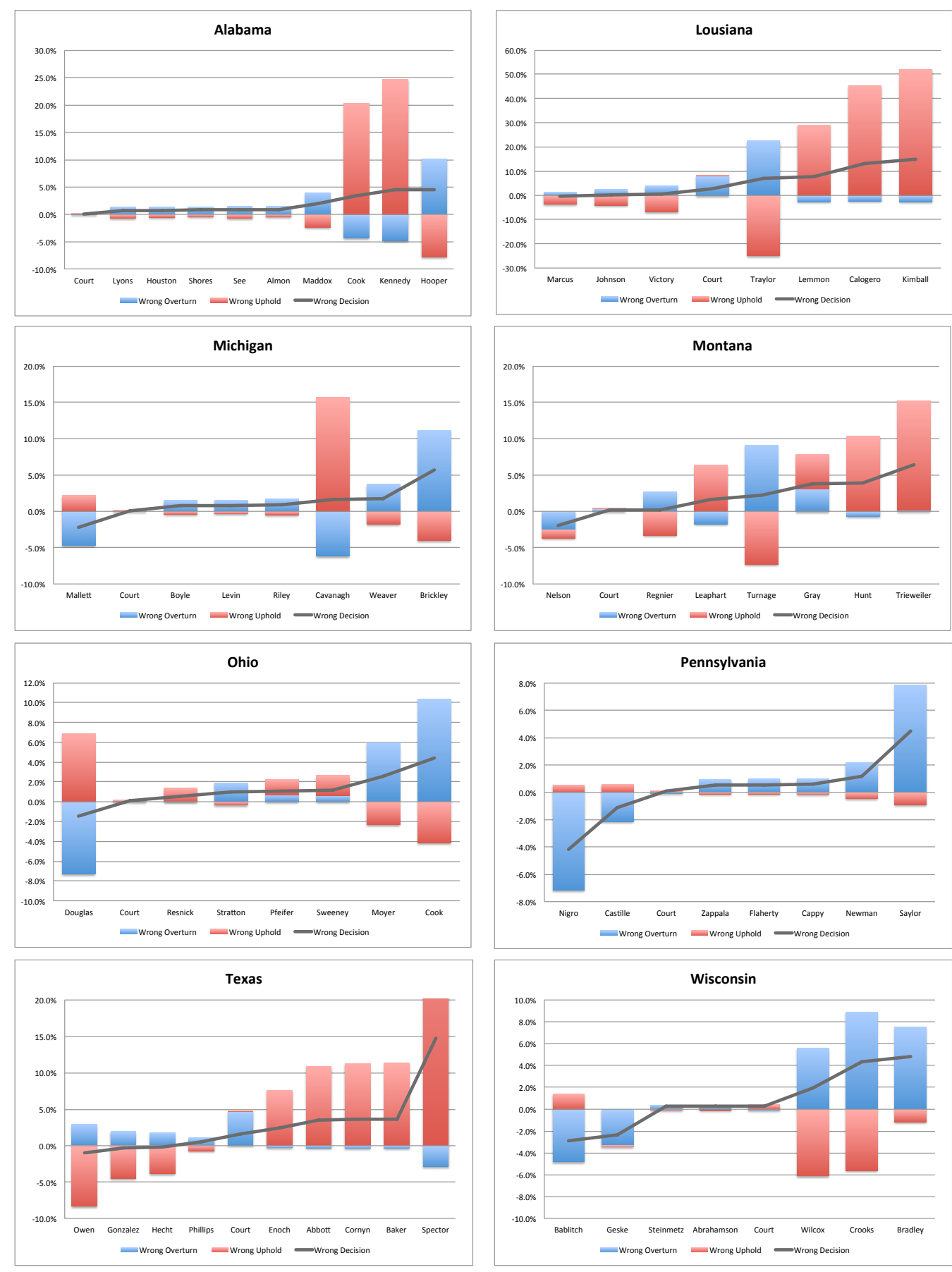

Figure 4: Counterfactual effect on the probability that each justice (and the Court) incorrectly votes to overturn (blue bars) and uphold (red bars) when the money slant changes from zero to the benchmark, $m^{1}$. Line plots the effect on the total probability of a mistake. 


\section{Appendix}

\subsection{Additional Tables}

Table 3: Case-Specific Data

\begin{tabular}{|c|c|c|c|c|c|c|c|c|c|}
\hline & Alabama & Louisiana & Michigan & Montana & Ohio & Pennsylvania & Texas & Wisconsin & Total \\
\hline Appeal & 0.705 & 0.728 & 0.969 & 0.944 & 0.636 & 1.000 & 0.814 & 0.674 & 0.764 \\
\hline Petitioner:Business & 0.407 & 0.160 & 0.247 & 0.162 & 0.221 & 0.306 & 0.535 & 0.140 & 0.292 \\
\hline Petitioner:Government & 0.075 & 0.295 & 0.216 & 0.056 & 0.233 & 0.129 & 0.125 & 0.341 & 0.187 \\
\hline Respondent:Business & 0.315 & 0.246 & 0.309 & 0.352 & 0.181 & 0.145 & 0.202 & 0.163 & 0.236 \\
\hline Respondent:Government & 0.108 & 0.160 & 0.191 & 0.257 & 0.531 & 0.339 & 0.191 & 0.217 & 0.277 \\
\hline Issue:Contracts & 0.452 & 0.160 & 0.185 & 0.324 & 0.076 & 0.161 & 0.255 & 0.124 & 0.209 \\
\hline Issue:Torts & 0.394 & 0.299 & 0.420 & 0.436 & 0.133 & 0.258 & 0.465 & 0.186 & 0.315 \\
\hline Legal:Discretion & 0.452 & 0.205 & 0.012 & 0.765 & 0.465 & 0.177 & 0.229 & 0.171 & 0.341 \\
\hline Legal:Evidence & 0.220 & 0.119 & 0.086 & 0.229 & 0.097 & 0.016 & 0.096 & 0.031 & 0.120 \\
\hline Legal:Standing & 0.191 & 0.190 & 0.130 & 0.168 & 0.290 & 0.226 & 0.263 & 0.194 & 0.225 \\
\hline Court Size & 9 & 7 & 7 & 7 & 7 & 7 & 9 & 7 & \\
\hline Decision: Unanimous & 0.506 & 0.672 & 0.494 & 0.659 & 0.584 & 0.710 & 0.707 & 0.860 & 0.633 \\
\hline Decision: Minimal Winning & 0.100 & 0.056 & 0.167 & 0.123 & 0.171 & 0.065 & 0.074 & 0.054 & 0.111 \\
\hline
\end{tabular}

Table 4: Justice-Specific Data

\begin{tabular}{|c|c|c|c|c|c|c|c|}
\hline State & Justice & PAJID & $\begin{array}{l}\text { Prior Judicial } \\
\text { Experience }(Y)\end{array}$ & \begin{tabular}{|c|} 
Prior Political \\
Experience $(0 / 1)$
\end{tabular} & $\begin{array}{c}\text { Years Until Next } \\
\text { Election (avg. 95-98) }\end{array}$ & $\begin{array}{l}\text { Years of Experience in } \\
\text { the Court (avg. 95-98) }\end{array}$ & CIT (avg. 95-98) \\
\hline \multirow{4}{*}{ Alabama } & mean & 36.6 & 7.5 & 0.1 & 2.0 & 10.6 & 35.1 \\
\hline & st.dev. & 12.6 & 9.2 & 0.4 & 1.7 & 8.9 & 0.0 \\
\hline & $\min$ & 8.1 & 0.0 & 0.0 & 0.0 & 0.3 & 35.1 \\
\hline & $\max$ & 48.6 & 25.0 & 1.0 & 4.5 & 27.5 & 35.1 \\
\hline \multirow{4}{*}{ Lousiana } & mean & 33.6 & 10.5 & 0.2 & 2.4 & 10.2 & 35.3 \\
\hline & st.dev. & 11.5 & 5.0 & 0.4 & 3.0 & 9.4 & 0.0 \\
\hline & $\min$ & 7.9 & 0.0 & 0.0 & 0.0 & 0.5 & 35.3 \\
\hline & $\max$ & 48.6 & 19.0 & 1.0 & 8.5 & 23.5 & 35.3 \\
\hline \multirow{4}{*}{ Michigan } & mean & 42.9 & 6.5 & 0.2 & 3.0 & 10.6 & 52.9 \\
\hline & st.dev. & 20.0 & 5.8 & 0.4 & 2.9 & 7.3 & 0.0 \\
\hline & $\min$ & 25.8 & 0.0 & 0.0 & 0.0 & 0.3 & 52.9 \\
\hline & $\max$ & 65.9 & 19.0 & 1.0 & 7.5 & 23.5 & 52.9 \\
\hline \multirow{4}{*}{ Montana } & mean & 34.0 & 0.9 & 0.1 & 2.1 & 6.2 & 37.4 \\
\hline & st.dev. & 17.7 & 2.1 & 0.3 & 2.5 & 5.3 & 0.0 \\
\hline & & 21.3 & 0.0 & 0.0 & 0.0 & 0.0 & 37.4 \\
\hline & $\max$ & 58.4 & 6.0 & 1.0 & 6.5 & 15.5 & 37.4 \\
\hline \multirow{4}{*}{ Ohio } & mean & 36.0 & 7.4 & 0.1 & 1.7 & 8.3 & 45.6 \\
\hline & st.dev. & 16.7 & 7.2 & 0.3 & 2.0 & 6.0 & \\
\hline & $\min$ & 21.3 & 0.0 & 0.0 & 0.0 & 0.0 & 37.4 \\
\hline & $\max$ & 56.7 & 22.0 & 1.0 & 5.5 & 19.5 & 46.4 \\
\hline \multirow{4}{*}{ Pennsylvania } & mean & 49.3 & 6.8 & 0.0 & 2.8 & 10.3 & 53.6 \\
\hline & st.dev. & 17.5 & 7.5 & 0.0 & 3.4 & 8.2 & 0.0 \\
\hline & $\min$ & 24.0 & 0.0 & 0.0 & 0.0 & 0.3 & 53.6 \\
\hline & $\max$ & 63.0 & 27.0 & 0.0 & 8.5 & 24.5 & 53.6 \\
\hline \multirow{4}{*}{ Texas } & mean & 27.2 & 5.0 & 0.1 & 0.8 & 6.7 & 37.6 \\
\hline & st.dev. & 11.7 & 6.2 & 0.4 & 1.5 & 5.0 & \\
\hline & $\min$ & 8.1 & 0.0 & 0.0 & -0.8 & 0.3 & 37.6 \\
\hline & $\max$ & 44.8 & 22.0 & 1.0 & 4.5 & 17.5 & 37.6 \\
\hline \multirow{4}{*}{ Wisconsin } & & 44.1 & 7.5 & 0.4 & 3.1 & 13.9 & 51.0 \\
\hline & st.dev. & 20.1 & 7.4 & 0.5 & 3.5 & 10.4 & 0.0 \\
\hline & $\min$ & 24.1 & 0.0 & 0.0 & 0.0 & 0.3 & 51.0 \\
\hline & $\max$ & 66.5 & 19.0 & $\begin{array}{l}1.0 \\
\end{array}$ & 9.0 & 32.5 & 51.0 \\
\hline
\end{tabular}


Table 5: Types and Strategies on Average, Benchmark Money Slant.

\begin{tabular}{|c|c|c|c|c|c|c|c|}
\hline & Justice & $\gamma_{i t 0}$ & $\gamma_{i t 1}$ & $\theta$ & $s^{*}$ & $\pi^{\exp }$ & $\pi^{S T}$ \\
\hline \multirow{9}{*}{$\begin{array}{c}\text { Alabama } \\
(\rho=0.68)\end{array}$} & Almon, Reneau P & 0.050 & 0.919 & 3.046 & 0.541 & 0.762 & 0.591 \\
\hline & Cook, Ralph D. & 0.282 & 0.977 & 2.575 & 0.224 & 0.259 & 0.421 \\
\hline & Houston, Gorman & 0.056 & 0.926 & 3.038 & 0.524 & 0.731 & 0.574 \\
\hline & Kennedy, Mark & 0.317 & 0.982 & 2.585 & 0.185 & 0.209 & 0.388 \\
\hline & Maddox, Alva Hugh & 0.022 & 0.897 & 3.285 & 0.615 & 0.883 & 0.708 \\
\hline & Shores, Janie L. & 0.047 & 0.923 & 3.099 & 0.540 & 0.761 & 0.593 \\
\hline & Hooper Sr., Perry O. & 0.024 & 0.817 & 2.890 & 0.687 & 0.912 & 0.695 \\
\hline & Lyons, Champ Jr. & 0.072 & 0.925 & 2.898 & 0.504 & 0.692 & 0.554 \\
\hline & See, Harold F. & 0.076 & 0.917 & 2.814 & 0.509 & 0.700 & 0.556 \\
\hline \multirow{7}{*}{$\begin{array}{l}\text { Louisiana } \\
(\rho=0.67)\end{array}$} & Calogero Jr., Pascal F. & 0.589 & 0.994 & 2.283 & -0.098 & 0.084 & 0.001 \\
\hline & Kimball, Catherine D. & 0.730 & 0.996 & 2.007 & -0.305 & 0.075 & 0.002 \\
\hline & Lemmon, Harry T. & 0.458 & 0.994 & 2.597 & 0.041 & 0.086 & 0.001 \\
\hline & Marcus Jr., Walter F. & 0.143 & 0.973 & 2.985 & 0.357 & 0.367 & 0.003 \\
\hline & Victory, Jeffrey P. & 0.167 & 0.926 & 2.413 & 0.400 & 0.537 & 0.003 \\
\hline & Johnson, Bernette Joshua & 0.170 & 0.946 & 2.557 & 0.373 & 0.475 & 0.003 \\
\hline & Traylor, Chet D. & 0.005 & 0.741 & 3.235 & 0.800 & 0.980 & 0.039 \\
\hline \multirow{7}{*}{$\begin{array}{c}\text { Michigan } \\
(\rho=0.64)\end{array}$} & Boyle, Patricia J. & 0.054 & 0.889 & 2.828 & 0.568 & 0.755 & 0.859 \\
\hline & Brickley, James $\mathrm{H}$. & 0.038 & 0.833 & 2.739 & 0.647 & 0.844 & 0.883 \\
\hline & Cavanagh, Michael F. & 0.216 & 0.965 & 2.595 & 0.303 & 0.322 & 0.755 \\
\hline & Levin, Charles L. & 0.046 & 0.888 & 2.906 & 0.581 & 0.780 & 0.868 \\
\hline & Mallett Jr., Conrad L. & 0.083 & 0.955 & 3.074 & 0.450 & 0.528 & 0.783 \\
\hline & Riley, Dorothy Comstock & 0.064 & 0.870 & 2.646 & 0.575 & 0.751 & 0.855 \\
\hline & Weaver, Elizabeth Ann & 0.077 & 0.841 & 2.426 & 0.588 & 0.751 & 0.850 \\
\hline \multirow{7}{*}{$\begin{array}{c}\text { Montana } \\
(\rho=0.58)\end{array}$} & Gray, Karla M. & 0.143 & 0.924 & 2.499 & 0.427 & 0.470 & 0.068 \\
\hline & Hunt Sr., William E. & 0.177 & 0.967 & 2.767 & 0.334 & 0.282 & 0.053 \\
\hline & Leaphart, W William & 0.165 & 0.972 & 2.883 & 0.338 & 0.266 & 0.049 \\
\hline & Nelson, Jim C. & 0.083 & 0.980 & 3.449 & 0.402 & 0.305 & 0.047 \\
\hline & Trieweiler, Terry & 0.245 & 0.953 & 2.362 & 0.292 & 0.304 & 0.063 \\
\hline & Turnage, Jean A. & 0.020 & 0.890 & 3.282 & 0.627 & 0.846 & 0.179 \\
\hline & Regnier, Jim & 0.071 & 0.928 & 2.927 & 0.502 & 0.586 & 0.084 \\
\hline \multirow{7}{*}{$\begin{array}{c}\text { Ohio } \\
(\rho=0.59)\end{array}$} & Cook, Deborah L. & 0.029 & 0.788 & 2.701 & 0.704 & 0.863 & 0.917 \\
\hline & Douglas, Andrew & 0.123 & 0.967 & 2.998 & 0.386 & 0.338 & 0.776 \\
\hline & Moyer, Thomas J. & 0.038 & 0.831 & 2.729 & 0.649 & 0.811 & 0.904 \\
\hline & Pfeifer, Paul E. & 0.102 & 0.937 & 2.805 & 0.453 & 0.496 & 0.838 \\
\hline & Resnick, Alice Robie & 0.069 & 0.900 & 2.765 & 0.536 & 0.652 & 0.871 \\
\hline & Sweeney Sr., Francis E. & 0.088 & 0.886 & 2.564 & 0.529 & 0.632 & 0.869 \\
\hline & Stratton, Evelyn Lundberc & 0.061 & 0.881 & 2.730 & 0.568 & 0.702 & 0.881 \\
\hline \multirow{7}{*}{$\begin{array}{l}\text { Pennsylvania } \\
(\rho=0.62)\end{array}$} & Cappy, Ralph J. & 0.043 & 0.833 & 2.683 & 0.640 & 0.816 & 0.994 \\
\hline & Castille, Ronald D. & 0.055 & 0.853 & 2.647 & 0.603 & 0.769 & 0.993 \\
\hline & Flaherty, John P. & 0.033 & 0.839 & 2.833 & 0.650 & 0.843 & 0.994 \\
\hline & Newman, Sandra Schultz & 0.047 & 0.807 & 2.547 & 0.659 & 0.820 & 0.994 \\
\hline & Zappala, Stephen A. & 0.033 & 0.846 & 2.865 & 0.644 & 0.840 & 0.994 \\
\hline & Nigro, Russell M. & 0.061 & 0.893 & 2.790 & 0.555 & 0.712 & 0.992 \\
\hline & Saylor, Thomas G. & 0.038 & 0.766 & 2.505 & 0.711 & 0.858 & 0.994 \\
\hline \multirow{9}{*}{$\begin{array}{c}\text { Texas } \\
(\rho=0.65)\end{array}$} & Abbott, Greg & 0.333 & 0.974 & 2.376 & 0.182 & 0.238 & 0.000 \\
\hline & Baker, James A. & 0.340 & 0.974 & 2.349 & 0.175 & 0.239 & 0.000 \\
\hline & Cornyn, John & 0.345 & 0.971 & 2.292 & 0.174 & 0.253 & 0.000 \\
\hline & Enoch, Craig T. & 0.296 & 0.972 & 2.452 & 0.219 & 0.258 & 0.000 \\
\hline & Gonzalez, Raul A. & 0.115 & 0.953 & 2.877 & 0.417 & 0.487 & 0.000 \\
\hline & Hecht, Nathan L. & 0.167 & 0.950 & 2.614 & 0.370 & 0.436 & 0.000 \\
\hline & Owen, Priscilla & 0.126 & 0.942 & 2.718 & 0.422 & 0.513 & 0.000 \\
\hline & Phillips, Thomas R. & 0.189 & 0.959 & 2.622 & 0.336 & 0.379 & 0.000 \\
\hline & Spector, Rose & 0.716 & 0.996 & 2.063 & -0.277 & 0.064 & 0.000 \\
\hline \multirow{7}{*}{$\begin{array}{l}\text { Wisconsin } \\
(\rho=0.69)\end{array}$} & Abrahamson,Shirley S. & 0.047 & 0.837 & 2.652 & 0.630 & 0.847 & 0.992 \\
\hline & Bablitch, William A. & 0.069 & 0.978 & 3.498 & 0.423 & 0.463 & 0.972 \\
\hline & Bradley, Ann Walsh & 0.055 & 0.765 & 2.318 & 0.689 & 0.859 & 0.992 \\
\hline & Geske, Janine P. & 0.064 & 0.872 & 2.660 & 0.572 & 0.787 & 0.991 \\
\hline & Steinmetz, Donald W. & 0.051 & 0.836 & 2.610 & 0.625 & 0.838 & 0.992 \\
\hline & Crooks, N. Patrick & 0.026 & 0.742 & 2.598 & 0.750 & 0.923 & 0.994 \\
\hline & Wilcox, John P. & 0.031 & 0.856 & 2.925 & 0.637 & 0.877 & 0.993 \\
\hline
\end{tabular}




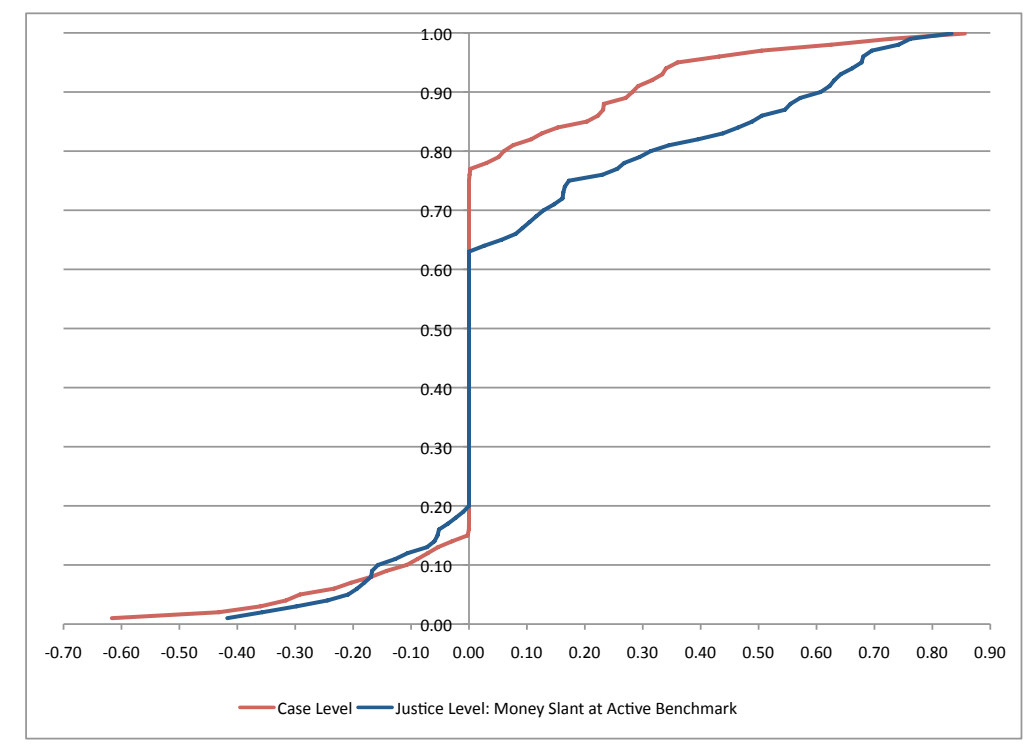

Figure 5: Empirical distribution of money slant at the justice/case level and of the justicespecific average money slant in the benchmark $m^{1}$.

Table 6: "Second-Stage" Estimates and Standard Errors for Alabama. Case-specific covariates at state-specific sample means, non-monetary individual-specific covariates at their values for the justices sitting in the court, and money slant of each justice at their sample average in the active benchmark $m^{1}$.

\begin{tabular}{|c|c|c|c|c|c|c|}
\hline Justice & $\gamma_{i t 0}$ & $\gamma_{i t 1}$ & $\theta$ & $S *$ & $\pi^{\exp }$ & $\pi^{S T}$ \\
\hline \multirow[t]{2}{*}{ Almon, Reneau P } & 0.050 & 0.919 & 3.045 & 0.541 & 0.761 & 0.589 \\
\hline & $(0.006)$ & $(0.006)$ & $(0.069)$ & $(0.012)$ & $(0.021)$ & $(0.064)$ \\
\hline \multirow[t]{2}{*}{ Cook, Ralph D. } & 0.282 & 0.977 & 2.575 & 0.224 & 0.259 & 0.419 \\
\hline & $(0.038)$ & $(0.003)$ & $(0.109)$ & $(0.036)$ & $(0.070)$ & $(0.113)$ \\
\hline \multirow[t]{2}{*}{ Houston, Gorman } & 0.056 & 0.926 & 3.038 & 0.524 & 0.731 & 0.572 \\
\hline & $(0.005)$ & $(0.005)$ & $(0.059)$ & $(0.010)$ & $(0.018)$ & $(0.063)$ \\
\hline \multirow[t]{2}{*}{ Kennedy, Mark } & 0.317 & 0.982 & 2.585 & 0.184 & 0.209 & 0.386 \\
\hline & $(0.049)$ & $(0.003)$ & $(0.127)$ & $(0.045)$ & $(0.083)$ & $(0.133)$ \\
\hline \multirow[t]{2}{*}{ Maddox, Alva Hugh } & 0.022 & 0.897 & 3.285 & 0.615 & 0.883 & 0.707 \\
\hline & $(0.005)$ & $(0.009)$ & $(0.103)$ & $(0.015)$ & $(0.033)$ & $(0.084)$ \\
\hline \multirow[t]{2}{*}{ Shores, Janie L. } & 0.047 & 0.923 & 3.099 & 0.539 & 0.761 & 0.591 \\
\hline & $(0.006)$ & $(0.006)$ & $(0.539)$ & $(0.011)$ & $(0.020)$ & $(0.063)$ \\
\hline \multirow[t]{2}{*}{ Hooper Sr., Perry O. } & 0.024 & 0.817 & 2.891 & 0.687 & 0.912 & 0.694 \\
\hline & $(0.009)$ & $(0.019)$ & $(0.175)$ & $(0.026)$ & $(0.051)$ & $(0.137)$ \\
\hline \multirow[t]{2}{*}{ Lyons, Champ Jr. } & 0.072 & 0.925 & 2.898 & 0.503 & 0.692 & 0.552 \\
\hline & $(0.007)$ & $(0.005)$ & $(0.062)$ & $(0.011)$ & $(0.019)$ & $(0.064)$ \\
\hline \multirow[t]{2}{*}{ See, Harold F. } & 0.076 & 0.917 & 2.814 & 0.508 & 0.700 & 0.555 \\
\hline & $(0.007)$ & $(0.006)$ & $(0.060)$ & $(0.011)$ & $(0.018)$ & $(0.066)$ \\
\hline
\end{tabular}

Prior $\rho=0.68(0.021)$ 


\subsection{Equilibrium in the Strategic Voting Model}

Let $\mu_{j t}: \mathbf{R} \rightarrow[0,1]$ denote the strategy of justice $j$ in case $t$, where $\mu_{j t}\left(s_{j t}\right) \equiv \operatorname{Pr}\left(v_{j t}=1 \mid s_{j t}\right)$. Given cutoff strategies with cutpoints $s_{i t}^{s t}, \operatorname{Pr}\left(v_{i t}=1 \mid \omega_{t}\right)=\int \mu_{i t}(s) \phi\left(\theta_{i t}\left[s-\omega_{t}\right]\right) d s=\left[1-\Phi\left(\theta_{i t}\left[s_{i t}^{s t}-\right.\right.\right.$ $\left.\left.\left.\omega_{t}\right]\right)\right]$. Therefore, letting $\mathcal{C}_{(n-1) / 2}^{i}$ denote the set of coalitions $C \subset N \backslash i$ with $(n-1) / 2$ members, $\left\{s_{i t}^{s t}\right\}_{i=1}^{n}$ is given by the $n$ equations

$$
\frac{\sum_{C \in \mathcal{C}_{(n-1) / 2}}\left(\prod_{j \in C}\left[1-\Phi\left(\theta_{j t}\left[s_{j t}^{s t}-1\right]\right)\right]\right)\left(\prod_{j \neq i, j \notin C} \Phi\left(\theta_{j t}\left[s_{j t}^{s t}-1\right]\right)\right)}{\sum_{C \in \mathcal{C}_{(n-1) / 2}}\left(\prod_{j \in C}\left[1-\Phi\left(\theta_{j t} s_{j t}^{s t}\right)\right]\right)\left(\prod_{j \neq i, j \notin C} \Phi\left(\theta_{j t} s_{j t}^{s t}\right)\right)} \frac{\phi\left(\theta_{i t}\left[s_{i t}^{s t}-1\right]\right)}{\phi\left(\theta_{i t} s_{i t}^{s t}\right)}=\frac{\pi_{i t}}{1-\pi_{i t}} \frac{1-\rho_{t}}{\rho_{t}}
$$

\subsection{Estimation}

As the discussion in Section 3 shows, the equilibrium voting behavior of the justices is completely characterized by the cutpoints: $\left\{s_{i t}^{s t}\right\}$ for the strategic model, and $\left\{s_{i t}^{e x p}\right\}$ for the expressive voting model. Given the cutpoints, we can write the likelihood of the justices' votes in case $t$ as

$$
\operatorname{Pr}\left(v_{t}\right) \equiv \sum_{\omega_{t}} \operatorname{Pr}\left(\omega_{t}\right) \prod_{i=1}^{n}\left[1-\Phi\left(\theta_{i t}\left[s_{i t}^{m}-\omega_{t}\right]\right)\right]^{v_{i t}} \Phi\left(\theta_{i t}\left[s_{i t}^{m}-\omega_{t}\right]\right)^{1-v_{i t}}, \quad m \in\{\exp , S T\} .
$$

The likelihood functions for the expressive and the strategic models are almost identical, except for the cutoff points: $s^{\text {exp }}$ for the expressive model, and $s^{s t}$ for the strategic model. ${ }^{23}$

Our estimation procedure has two parts, which we describe in order.

Estimation: First step. We introduce the following notation:

$$
\begin{aligned}
& \text { Priors: } \quad \rho \equiv \operatorname{Pr}\left(\omega_{t}=1\right) \quad \text { Voting Probs.: } \quad \gamma_{i, 1} \equiv \operatorname{Pr}\left(v_{i t}=1 \mid \omega_{t}=1\right) \\
& 1-\rho=\operatorname{Pr}\left(\omega_{t}=0\right) \quad \gamma_{i, 0} \equiv \operatorname{Pr}\left(v_{i t}=1 \mid \omega_{t}=0\right)
\end{aligned}
$$

Our empirical model accommodates case-level heterogeneity by allowing the reduced-form parameters of the model - which are recovered in the first step of the estimation procedure to depend quite flexibly on observable characteristics $X_{t}$. Specifically, we parameterize justices' priors in case $t, \rho_{t} \equiv \operatorname{Pr}\left(\omega_{t}=1\right)$, as a logit probability which depends on the characteristics $X_{t}$ :

$$
\rho\left(X_{t} ; \beta\right) \equiv \frac{\exp \left(X_{t}^{\prime} \beta\right)}{1+\exp \left(X_{t}^{\prime} \beta\right)}, \quad \in[0,1] .
$$

\footnotetext{
${ }^{23}$ We argued that any equilibrium in the expressive and strategic voting models must be in cutoff strategies. In the strategic voting model, however, it is possible that equilibrium is not unique; i.e., that given a prior $\rho$ and types $\left(\theta_{i}, \pi_{i}\right)$ for $i=1, \ldots, n$, there is more than one vector of cutpoints $s^{s t}$ solving (3). Here we assume that if there are multiple equilibria, justices consistently play the same equilibrium whenever the characteristics of the problem are unchanged. It should be noted, however, that in the estimation, for any vector of conditional voting probabilities in the first stage (see Section 7.3), we recover the types $\left(\theta_{i}, \pi_{i}\right)$ uniquely.
} 
Because the prior probability $\rho_{t}$ varies across cases, so will the equilibrium strategies $s_{i t}^{*}$, and hence so will the justice-specific conditional probabilities of voting to overturn $\gamma_{i t, 1}$ and $\gamma_{i t, 0}$. Accordingly, we also parameterize these probabilities to depend upon $X_{t}$ (covariates for case $t$ ) and $Z_{i}$ (covariates for justice $i$ ) in the following way, which also restricts $\gamma_{i, t, 1} \geq \gamma_{i, t, 0}$, for all $X_{t}$ :

$$
\begin{aligned}
\gamma_{i, 0}(\zeta, \eta) & =\frac{\exp \left(Z_{i}^{\prime} \zeta+X_{t}^{\prime} \eta\right)}{1+\exp \left(Z_{i}^{\prime} \zeta+X_{t}^{\prime} \eta\right)}, \quad \in[0,1] \\
\gamma_{i, 1}(\zeta, \eta, \alpha, \delta) & =\frac{\gamma_{i, 0}+\exp \left(Z_{i}^{\prime} \alpha+X_{t}^{\prime} \delta\right)}{1+\exp \left(Z_{i}^{\prime} \alpha+X_{t}^{\prime} \delta\right)}, \quad \in\left[\gamma_{i, 0}(\zeta, \eta), 1\right] .
\end{aligned}
$$

In the first stage, we estimate the parameters $(\beta, \delta, \eta)$ as well as the justice-specific variables $\left(\alpha_{i}, \zeta_{i}\right)$ for $i=1, \ldots, n$. For this, we maximize the following likelihood function, which corresponds to the reduced-form likelihood function for bids in both the expressive and strategic voting models:

$$
\begin{aligned}
\max _{\alpha, \beta, \zeta, \eta, \delta} \sum_{t} & \log \left[\rho\left(X_{t} ; \beta\right) \cdot \prod_{i=1}^{n}\left\{\gamma_{i, 1}(\zeta, \eta, \alpha, \delta)^{v_{i t}}\left(1-\gamma_{i, 1}(\zeta, \eta, \alpha, \delta)\right)^{1-v_{i t}}\right\}\right. \\
& \left.+\left(1-\rho\left(X_{t} ; \beta\right)\right) \cdot \prod_{i=1}^{n}\left\{\gamma_{i, 0}(\zeta, \eta)^{v_{i t}}\left(1-\gamma_{i, 0}(\zeta, \eta)\right)^{1-v_{i t}}\right\}\right] .
\end{aligned}
$$

Given the MLE estimates of $\hat{\zeta}, \hat{\eta}, \hat{\alpha}, \hat{\delta}$, we can compute the corresponding priors $\hat{\rho} \equiv \rho\left(X_{t}, \hat{\beta}\right)$ as well as vote probabilities $\hat{\gamma}_{i, 0} \equiv \gamma_{i, 0}(\hat{\zeta}, \hat{\eta})$ and $\hat{\gamma}_{i, 1} \equiv \gamma_{i, 1}(\hat{\zeta}, \hat{\eta}, \hat{\alpha}, \hat{\beta})$ for any vector of covariates $\left(X_{t}, Z_{t}\right)$.

Second step. Using the estimates of the two justice-specific vote probabilities $\hat{\gamma}_{i, 1}$ and $\hat{\gamma}_{i, 0}$, from the first step, we recover the equilibrium strategies and the two structural parameters, $\pi_{i}$ and $\theta_{i}$, for each justice $i$. Recall our earlier assumptions that justice $i$ 's private information is $s_{i t}=\omega_{t}+\frac{1}{\theta_{i}} \varepsilon_{i t}$, with $\varepsilon_{i t} \sim \mathcal{N}(0,1)$. Then $\left.\gamma_{i, 1} \equiv 1-\Phi\left(\theta_{i}\left[s_{i}^{*}-1\right]\right)\right)$ and $\gamma_{i, 0} \equiv\left(1-\Phi\left(\theta_{i} s_{i}^{*}\right)\right)$. Solving these equations for $\theta_{i}$ and $s_{i}^{*}$ given $\hat{\gamma}_{i, 1}$ and $\hat{\gamma}_{i, 0}$ (and substituting $\Phi^{-1}\left(\gamma_{i, 1}\right)=-\Phi^{-1}\left(1-\gamma_{i, 1}\right)$ ) gives $^{24}$

$$
\hat{\theta}_{i}=\Phi^{-1}\left(1-\hat{\gamma}_{i, 0}\right)-\Phi^{-1}\left(1-\hat{\gamma}_{i, 1}\right) ; \quad \hat{s}_{i}=\frac{\Phi^{-1}\left(1-\hat{\gamma}_{i, 0}\right)}{\Phi^{-1}\left(1-\hat{\gamma}_{i, 0}\right)+\Phi^{-1}\left(\hat{\gamma}_{i, 1}\right)}
$$

In order to recover the bias parameter $\pi_{i}$, we use the equilibrium voting condition, which differs between the expressive and strategic models. In the case of the expressive voting model, this is given by

$$
\frac{\phi\left(\theta_{i}\left[\hat{s}_{i}-1\right]\right)}{\phi\left(\theta_{i} \hat{s}_{i}\right)}=\frac{\hat{\pi}_{i}^{\exp }}{1-\hat{\pi}_{i}^{\exp }} \frac{1-\hat{\rho}}{\hat{\rho}},
$$

while in the strategic voting model this is given by the system of equations (3). For both models, plugging in our estimates of $\theta_{i}$ and $\hat{s}_{i}$ into the appropriate equilibrium condition allows us to

\footnotetext{
${ }^{24}$ Note that the estimate of $i$ 's information quality is increasing in the probability of correctly voting to overturn, $\gamma_{i, 1}$, and decreasing in the probability of incorrectly voting to overturn, $\gamma_{i, 0}$. The estimate of the equilibrium cutpoint, instead, is a decreasing function of the ratio between $\Phi^{-1}\left(\hat{\gamma}_{i, 1}\right)$ and $\Phi^{-1}\left(1-\hat{\gamma}_{i, 0}\right)$. Thus $\hat{s}_{i}$ is (roughly) decreasing in the ratio of the probability of correctly voting to overturn $\left(\gamma_{i, 1}\right)$ relative to the probability of correctly voting to uphold $\left(1-\gamma_{i, 0}\right)$.
} 
recover estimates of $\hat{\pi}_{i}^{e x p}$ and $\hat{\pi}_{i}^{s t}$ for the expressive and strategic models, respectively. Note that, when the voting probabilities $\gamma_{i .0}$ and $\gamma_{i, 1}$ are case-specific and depend on the covariates $X$ and $Z$, then so will the model parameters $\theta$ and $\pi$.

Note that, in recovering $\theta_{i}$, it was not necessary to specify whether justices vote expressively or strategically. An assumption regarding strategic or expressive voting is required only for recovering $\pi_{i}$. This distinction between $\theta_{i}$ and $\pi_{i}$ is a remarkable property of this problem. It implies that the precision estimate is independent of whether justices care about the court ruling or about their own vote being correct, and therefore of whether justices use the information contained in the event of them being pivotal or simply best respond to their own private information. ${ }^{25}$

\subsection{The Environment of Judicial Decisions}

The analysis in the paper focused on how contributions affect the characteristics and voting behavior of the supreme court justices serving in the court. Money, however, is only one of several factors influencing the types and voting behavior of members of the court. The goal of this section is to put the effect of money in perspective, relating it to the changes caused by other, non-monetary factors. In particular, we focus here on two factors: (i) differences in preferences across voters, and (ii) justices' experience in the court, and discuss other factors summarily.

Voters' Characteristics. In the econometric model, we allow justices' types and voting behavior to vary with voters' characteristics. Here we employ the measure of citizen ideology (CIT) proposed by Berry, Ringquist, Fording, and Hanson (1998). The first-stage estimates for the coefficients $\zeta_{2}^{C}$ and $\alpha_{2}^{C}$ of CIT in the conditional voting probabilities $\gamma_{0}$ and $\gamma_{1}$ are negative and statistically significant (Table 6 ). The estimates $\zeta_{2}^{C}=-0.063(0.002) \approx \alpha_{2}^{C}=-0.066(0.003)<0$ suggest that CIT predominantly affects justices' bias (though not entirely, because of the nonlinearity in the specification). Figure 4 illustrates the magnitude of the effect of CIT on justices' bias and quality of information. The horizontal axis represents the counterfactual bias of individual justices in all eight states when facing the voters of the most conservative state in the sample (Montana), as measured by the CIT variable. The vertical axis represents the change in bias corresponding to a change in CIT to the level of a moderate state (Alabama) and to the level of the most liberal state (Pennsylvania).

\footnotetext{
25 See Iaryczower and Shum (2011) and Iaryczower, Lewis, and Shum (2011) for a discussion of parameter identification for our model.
} 

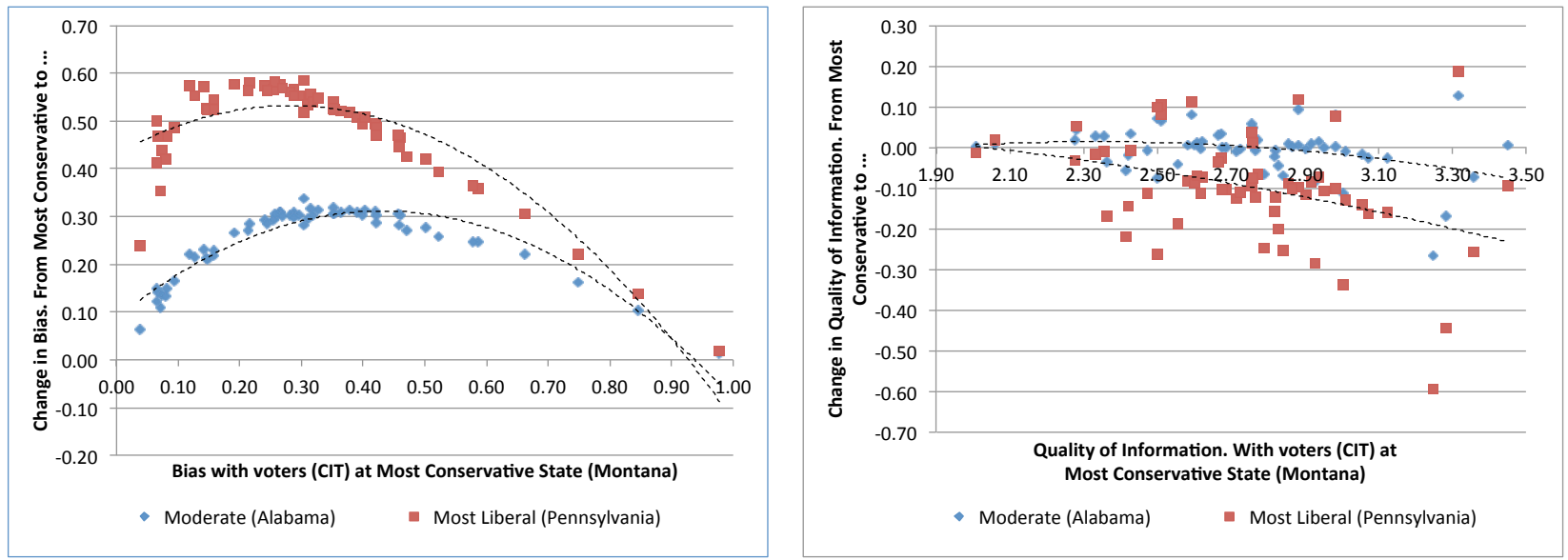

Figure 6: The left panel plots individual justices' bias when CIT is fixed at the levels of the most conservative state in the sample (Montana) in the horizontal axis, and the corresponding change in bias when CIT is fixed at the level of that of voters in the centrist state in the sample (Alabama) and the most liberal state in the sample (Pennsylvania). The right panel shows the corresponding figure for quality of information.

The results show a very significant change in bias in response to these changes in CIT. Changing from the voters in the most conservative state (Montana) to the voters of the intermediate liberal/conservative state (Alabama) increases the bias towards upholding by an average of 0.21. The change in bias peaks at about $\Delta \pi \approx 0.3$ for initial bias levels $\pi \in[0.2,0.4]$. Thus, a justice that would have overturned a decision of the lower court when facing Montana voters if the probability that the Petitioner is correct was at least $30 \%$ would require a probability of at least 60 $\%$ to overturn when facing the more moderate Alabama voters. Changing from the voters in the most conservative state (Montana) to the voters of the most liberal state (Pennsylvania) increases the pro-upholding bias by an average of 0.48 . The change in bias peaks at about $\Delta \pi \approx 0.6$ for initial bias levels $\pi \in[0.1,0.3]$. Thus, a justice that would have overturned when facing Montana voters if the probability that the Petitioner is correct is at least $20 \%$ would require a probability of at least $80 \%$ to overturn when facing the more liberal Pennsylvania voters. To put these results in perspective, eliminating the money slant in the benchmark increases $\pi$ by 0.20 or more for only $10 \%$ of justices, and increases $\pi$ by 0.22 or more for only $5 \%$ of justices.

Experience. In the econometric model, we allow justices' types and voting behavior to vary with their prior judicial experience, and their experience in the court. The coefficient estimates for the experience variables are statistically significant, but the magnitude of the estimates is small compared to the effect of the money slant. Additional years of experience in the court have a small but positive effect on quality of information and a negligible effect on bias: increasing experience in the court from zero to ten years increases the average quality of information between 0.12 and 0.13 for $90 \%$ of justices, and changes the bias of $90 \%$ of justices between 0.014 and 0.036 . Additional years of prior judicial experience have a small but negative effect on quality of information, and a negligible effect on bias: increasing prior judicial experience from zero to ten years reduces the average quality of information between -0.08 and -0.07 for $90 \%$ of justices, and changes the bias 
of $90 \%$ of justices between -0.004 and 0.002 .

Substantive Issues. Justices decide disputes on different types of cases, including differences in both substantive and legal issues. Within substantive issue areas, we distinguish between civil government, contracts and torts cases. Outcomes are statistically significantly different across issue areas, although the differences are not always large in magnitude. First, the prior probability that the decision of the lower court should be overturned is about 0.6 in both civil government cases and torts, but is significantly larger (0.73) in contracts. Justices biases are basically unchanged between torts and civil government cases (for $90 \%$ of justices, the difference in bias is between -0.012 and 0.016 ), but most justices become more pro-defendant in contracts cases: $90 \%$ of justices' bias increase between 0.097 and 0.267 , and for more than $50 \%$ of justices, bias increases more than 0.2. Quality of information is substantially larger in both contracts and torts cases, compared to civil government cases. For $90 \%$ of justices, the change in quality of information in contracts (tort) cases vis a vis civil government is between 0.245 and $0.317(0.302$ and 0.326$)$.

Legal Issues. Outcomes also vary significantly with differences in legal issues across cases. Comparing with the base category, the average quality of information in cases involving issues of legal discretion is between 0.19 and 0.32 points larger than in the base legal class for $90 \%$ of individuals, but only between 0.02 and 0.17 points larger for issues of evidence, and between -0.36 and -0.29 smaller for issues of legal standing. Similarly, judges are less inclined to reverse the decision of lower court when considering legal issues of evidence and discretion than in issues of legal standing. Comparing with the base category, the average bias in cases involving issues of legal discretion is between 0.05 and 0.15 points larger than in the base legal class for $90 \%$ of individuals, and between 0.07 and 0.22 points larger for issues of evidence, but between -0.10 and 0.04 points smaller for issues of legal standing.

Type of Parties to the Case. The identity of the parties involved in a case summarizes relevant information about the details of the legal disputes. In tort cases, for example, individuals will tend to bring forward different legal arguments than businesses or a government. Businesses, governments and individuals might also on average differ in the quality of the legal representation, or on the side of the substantive issue they take in each case. To capture these differences, in the specification we distinguish Business and Governments from other types of petitioners and respondents, including individuals, schools, and other organizations. To summarize the results, we fix the respondent at the individuals category, and change the type of petitioner from individuals to government and business. The results suggest that all else equal, on average justices are more inclined to favor businesses over government, and government over individuals. In fact, when we consider a government (business) petitioner instead of an individual, $90 \%$ of justices are more inclined to overturn, with a change in the bias parameter of between 0.21 and 0.51 (between 0.056 and 0.17 for Business), and $50 \%$ of justices have a change in bias of at least 0.40 (0.08). At the same time, the prior that the decision of the lower court should be overturned is lower when the petitioner is Government (0.70) or Business (0.71), instead of an individual (0.75). ${ }^{26}$

\footnotetext{
${ }^{26}$ When we fix the petitioner as an individual and change the type of respondent from individual to government and business, on average bias also changes towards the petitioner. This is counterintuitive.
} 


\section{5 "Narrow" IG Classification.}

In the paper we study the effect on a justice's characteristics and voting behavior of the aggregate contributions of the group of individuals and organizations sharing a preferred legal position of the court on a given issue. In our main results, we define these interest groups using a broad classification, distinguishing contributions from business, unions, (non-corporate) lawyers, and education organizations. We have also considered a more narrow classification of interest groups, in which we distinguish among different business sectors. To do this, we begin assigning contributions to groups according to the detailed original coding of the National Institute of Money in State Politics. ${ }^{27}$ We then further aggregate these initial classes into a broader sector classification. The next table lists the interest groups defined in this way, and the total contributions per group. Table 8 presents the first-stage estimates of our model, using the narrow interest group classification. The table shows that all our main results are qualitatively unchanged.

\begin{tabular}{|l|r|r|r|r|}
\hline & Contributions & & \\
\hline "Narrow" Lobby & 1995 & 1996 & 1997 & 1998 \\
\hline ACCOUNTANT & 117708 & 128860 & 147960 & 168985 \\
AGRICULTURE & 177833 & 340229 & 358354 & 440269 \\
AUTO & 124967 & 238172 & 268972 & 426723 \\
BUSINESS ASSOCIATIONS & 322984 & 844440 & 914990 & 1348005 \\
CHEMICAL & 86941 & 150088 & 184473 & 247651 \\
CONSTRUCTION & 274134 & 535883 & 640893 & 821673 \\
EDUCATION & 109932 & 133394 & 144169 & 156934 \\
ELECTRONICS & 47815 & 57689 & 77914 & 85539 \\
ENTERTAINMENT & 19400 & 23757 & 39707 & 53789 \\
FINANCE & 520620 & 796828 & 912678 & 1105330 \\
FOOD & 153058 & 210943 & 240393 & 297368 \\
HEALTHCARE & 96333 & 146850 & 165802 & 198752 \\
HEALTHCARE PROFESSIONAL & 502663 & 774633 & 828273 & 971441 \\
INSURANCE & 393887 & 530587 & 592838 & 731349 \\
LAWYERS & 8524457 & 10811613 & 11822418 & 13349244 \\
MACHINERY & 86357 & 142957 & 190377 & 247317 \\
OIL/MINING & 475288 & 724547 & 814863 & 972412 \\
PHARMACEUTICAL & 58900 & 65950 & 73510 & 84610 \\
REAL ESTATE & 325252 & 456525 & 528156 & 653223 \\
RESTAURANTS & 18800 & 61172 & 65422 & 82755 \\
RETAIL & 62048 & 141898 & 155958 & 220954 \\
TEXTILES & 16950 & 30950 & 38450 & 45075 \\
TOBACCO & 15415 & 29265 & 31340 & 37252 \\
TRANSPORTATION & 68818 & 107208 & 130258 & 161008 \\
UNION & 595187 & 755586 & 768436 & 860191 \\
UTILITIES & 136844 & 152151 & 201751 & 253051 \\
UNMATCHED.CASE.DATABASE & 11123442 & 15586438 & 16749501 & 18857162 \\
\hline Grand TOtal & 24456033 & 33978612 & 37087855 & 42878061 \\
\hline
\end{tabular}

Table 7: "Narrow" Interest Group Coding

On the other hand, the prior probability that the petitioner is right changes from 0.75 to 0.55 when the respondent is Government and 0.57 when the respondent is Business.

${ }^{27}$ See http://www.followthemoney.org/Institute/about_data.phtml. 
Table 8: Narrow Interest Group Coding: Coefficients of the common prior function $\rho\left(X_{t}\right)$, and the individual state-contingent probabilities of voting to overturn the decision of the lower court, $\gamma_{0}\left(X_{t}, Z_{i t}\right)$ and $\gamma_{1}\left(X_{t}, Z_{i t}\right)$.

\begin{tabular}{|c|c|c|c|c|}
\hline & & $\rho$ & $\gamma_{i t 0}$ & $\gamma_{i t 1}$ \\
\hline \multirow{22}{*}{$\begin{array}{c}\text { Case } \\
\text { Specific }\end{array}$} & \multirow{2}{*}{ Constant } & 1.781 & 1.692 & 5.279 \\
\hline & & (9.780) & (8.224) & (19.003) \\
\hline & \multirow{2}{*}{ Appeal } & -0.630 & -0.106 & -0.556 \\
\hline & & $-(3.831)$ & $-(1.682)$ & $-(6.842)$ \\
\hline & \multirow{2}{*}{ Petitioner:Business } & -0.281 & 1.271 & 0.903 \\
\hline & & $-(1.711)$ & (11.929) & (6.310) \\
\hline & \multirow{2}{*}{ Petitioner:Govt } & -0.299 & 0.539 & 0.230 \\
\hline & & $-(1.848)$ & (4.356) & $(2.284)$ \\
\hline & \multirow{2}{*}{ Respondent:Business } & -0.399 & -0.837 & -0.095 \\
\hline & & $-(1.842)$ & $-(5.019)$ & $-(1.320)$ \\
\hline & \multirow{2}{*}{ Respondent:Govt } & -0.899 & -0.349 & 0.531 \\
\hline & & $-(5.325)$ & $-(3.235)$ & $(5.680)$ \\
\hline & \multirow{2}{*}{ Issue:Contracts } & 0.238 & 0.178 & 0.271 \\
\hline & & (1.339) & (1.509) & $(2.650)$ \\
\hline & \multirow{2}{*}{ Issue:Torts } & -0.198 & -0.020 & 0.444 \\
\hline & & $-(1.188)$ & $-(0.375)$ & $(4.796)$ \\
\hline & \multirow{2}{*}{ Legal:Discretion } & -0.356 & -0.845 & -0.355 \\
\hline & & $-(2.510)$ & $-(7.391)$ & $-(4.417)$ \\
\hline & \multirow{2}{*}{ Legal:Evidence } & 0.108 & -1.493 & -0.723 \\
\hline & & (0.778) & $-(4.856)$ & $-(7.393)$ \\
\hline & \multirow{2}{*}{ Legal:Standing } & -0.414 & 0.062 & -0.556 \\
\hline & & $-(2.374)$ & $(0.872)$ & $-(5.793)$ \\
\hline \multirow{6}{*}{$\begin{array}{l}\text { Justice } \\
\text { Specific }\end{array}$} & \multirow{2}{*}{ PAJID } & & -0.012 & 0.009 \\
\hline & & & $-(3.166)$ & (4.049) \\
\hline & \multirow{2}{*}{ Judicial Experience } & & -0.006 & -0.010 \\
\hline & & & $-(1.499)$ & $-(2.505)$ \\
\hline & \multirow{2}{*}{ Political Experience } & & 0.083 & 0.750 \\
\hline & & & $(0.812)$ & (3.635) \\
\hline \multirow{14}{*}{$\begin{array}{l}\text { Justice/Case } \\
\text { Specific }\end{array}$} & \multirow{2}{*}{$\begin{array}{l}\text { Years of Experience } \\
\text { in the Court }\end{array}$} & & -0.019 & -0.001 \\
\hline & & & $-(2.275)$ & $-(1.139)$ \\
\hline & \multirow{2}{*}{ CIT } & & -0.073 & -0.075 \\
\hline & & & $-(12.374)$ & $-(12.637)$ \\
\hline & \multirow{2}{*}{$\mathrm{CIT}^{*}$ termremain } & & -0.001 & 0.000 \\
\hline & & & $-(1.674)$ & $(0.986)$ \\
\hline & \multirow{2}{*}{ Contributions } & & 2.666 & 3.319 \\
\hline & & & (2.058) & (2.959) \\
\hline & Contributions * & & 4.778 & -0.973 \\
\hline & ProRespondent & & (1.102) & $-(1.010)$ \\
\hline & Contributions(-i) & & -2.265 & -3.908 \\
\hline & & & $-(1.742)$ & $-(4.710)$ \\
\hline & Contributions * & & -0.165 & -0.256 \\
\hline & termremain & & $-(0.517)$ & $-(1.077)$ \\
\hline
\end{tabular}

Note: t-statistics in parenthesis. 